\title{
A typological look at kinship terms, colour terms and numbers in Finnish Sign Language
}

\author{
Ritva Takkinen, Tommi Jantunen, and Irja Seilola
}

\section{Introduction}

This chapter deals with Finnish sign language (FinSL). FinSL is the majority sign language in Finland's deaf community, which has about 4000-5000 deaf sign language users. In the deaf community there is also a small minority language, Finland-Swedish Sign Language (FinSSL) with about 140 users. In this paper FinSSL is not discussed. FinSL has its origin in the old Swedish Sign Language (SSL). The first deaf teacher of the deaf, Carl Oscar Malm (1826-1863), studied between 1834 and 1845 in Sweden in Manilla (formerly Manhem) school, where he learned the sign language used in the school. When he returned to Finland and started to teach Finnish deaf people, this language was then mixed with the various ways of communication already used by Finnish deaf people (Salmi 2010). It has been estimated that FinSL was a linguistically separate from the (old) SSL already by the beginning of the $20^{\text {th }}$ century (Jantunen 2001).

Kinship terms, colour terms, and numbers, are often used to compare languages from the point of view of how their users categorise the world. These three domains are also the starting point of the larger Sign Language Typology project ${ }^{1}$ to which this study participates by looking at the semantic fields of kinship and colour as well as the number system in the lexicon of FinSL. In particular, the study aims at investigating the following questions provided in the Sign Language Typology project:

1) What is the semantic and morphological structure of kinship paradigms in FinSL (core vs. non-core kinship and blended families)?

2) Are there gender and age distinctions?

3) Are the kinship terms semantically related to Finnish?

4) What are the main colour terms (lexical signs for colours) used in FinSL? 
5) What other ways are there to talk about colours?

6) What is the relationship between the colour terms of FinSL and Finnish, the surrounding spoken language?

7) What is the number system like in FinSL (cardinal and ordinal numbers)?

8) How does FinSL use numeral incorporation in the lexicon?

9) What is the relationship between the number system of FinSL and Finnish?

The research questions are motivated by the questionnaires provided in the typology project. In order to answer the questions, signs referring to colours, numbers and family relations were elicited and recorded from dialogues between native FinSL signers involved in various specifically designed game activities. The game to elicit kinship terms and diagrammatic representations of kinship was a family tree game with a task to plan the guest list (including only relatives) for a wedding or other party. The material that was used to elicit the colour terms (basic and non-basic colour terms as well as distinctions between light and dark colours), in turn, consisted of coloured plastic chips and coloured pictures. One player described the colour of different things in their picture and the other player had to find that colour from among his/her coloured chips. The other task in eliciting colours was to name the colours of all the coloured chips. Finally, the material to elicit numbers (cardinal numbers from 0 to 100 as well as monetary terms and numbers above 100) consisted of cards with instructions for different kinds of sums, divisions, multiplications, etc., that the players had to follow. Another game in number elicitation was a bargaining game in which a buyer and a seller had to negotiate about a price.

Three pairs of FinSL users took part in the recorded discussions, so we have for analysis the signing of six people. After analysis of the video material the typological questionnaires were filled in. In addition, other research on colour, kinship terms and numbers in FinSL was used to get the picture of each semantic field. In particular, the study of numbers drew heavily on a dictionary of FinSL numerals and numeral expressions (Jantunen and Savolainen 2002).

In this chapter, kinship terms, colour terms and numbers are discussed in separate sections. Kinship and colour are discussed primarily in contrast to typological findings and on a lexical level whereas numbers in FinSL are approached descriptively and mainly on phonological and morphological levels. We consider our approach to be ontologically motivated: in terms of semantic domains, numbers form a more abstract, detailed and broader system than kinship and colour terms. 


\section{Kinship terms}

In this section we deal with the kinship system of FinSL and answer the first three research questions (section 1). We begin by reviewing the crosslinguistic research done on kinship systems in spoken languages.

\subsection{Typological background}

Every human language and culture has ways to express family relations; the terms by which it is done vary from language to language and from culture to culture. In spoken languages kinship terminology has often been studied (e.g. Wallace and Atkins 1960, Shusky 1965, Greenberg 1966, 1990), but in sign languages few studies are found in the literature (Peng 1974, Woodward 1978, Massone \& Johnson 1991, Nyst 2007, Wilkinson 2009, Geer 2011). Greenberg (1966) in his study of 120 spoken languages tried to find linguistic universals in kinship terminology and found several universal hierarchies.

Woodward (1978) wanted to test how Greenberg's universal hierarchies work in signed languages. He conducted a comparative study on kinship terms, choosing 20 sign languages that he divided according to a hypothesised relationship to six groups: a French sign language group, a British sign language group, an Asian SL group, a South American SL group, an Unknown affiliation, and Indigenous. He defined a basic kinship term as being 1) a native sign showing no evidence of borrowing from other languages (e.g. initialised signs), and 2) a monomorphemic or polymorphemic sign referring to a consanguineal kinsman or woman, i.e. those related by blood. Following his restrictions on what he considered to be proper kinship terms, he found altogether 114 terms in 20 sign languages. The number of native kinship terms varied from three to twelve in different sign languages. Nearly all sign languages had at least some primary kinship terms representing nuclear relations (mother, father, brother or sister, child). Sign languages showed variation in consanguineal kinship terms with respect to gender, age, generation and lineality.

Sign languages are minority languages that are in contact with the majority languages spoken in their countries. Research into kinship terminology in sign languages (Peng 1974, Woodward 1978, Massone \& Johnson 1991, Nyst 2007, Wilkinson 2009, Geer 2011) has shown that all the languages that were studied categorised kinship terms either in descriptive or classificatory terms. Both similarities and differences have been found in the categorisation of kinship terms between sign languages and the majority languages 
with which these sign languages are in contact. In addition, some interesting structural features have been shown; for example, in Japanese sign language the fingers of the hand are used in a culturally typical order to express family relations. One difference seems to be that in sign languages, kinship terms are used as referential but not as vocative terms (addressing family members) (Peng 1974, Nyst 2007). In some sign languages kinship terms can have borrowed terms from the majority spoken language by using fingerspelling or gender marking, e.g. in Argentinean sign language (Massone \& Johnson 1991).

Peng (1974) found that in Japanese sign language (JSL) kinship terms can be basic signs for lineal and nuclear relationships, and derivative signs for collateral and affinal relationships. Derivative signs are constructions of two or more basic signs (e.g. father younger sister). In JSL, handshape marks gender: the thumb denotes first and second ascending male, and the little finger denotes first and second ascending female. This pattern is present also in spousal terms. Iconicity is present in grandparental terms as a bending of the thumb or little finger and also in sibling terms as an upward movement (older brother or sister) or a downward movement (younger brother or sister). Gender marking with a handshape is also found in Korean sign language (Zeshan et al. forthcoming).

Wilkinson (2009) investigated the kinship terms of 40 sign languages in North and South America, Europe, Africa and Asia. He studied the sign language dictionaries of these languages and compared the ways of expressing kinship. He found that the languages used different strategies to construct kinship terms. Most of the languages used one lexical unit in these terms, but a few of them used two or more units. Sign languages also varied in the use of initialisation in kinship terms: some of the languages used no initialisation, while others used it in more than $50 \%$ of the terms (e.g. Irish sign language 15/16). Neither the number of lexical units nor the number of initialised handshapes was, according to Wilkinson's results (2009), a consistent definer of markedness in kinship terms. Wilkinson (2009) also found that location functions as a potential gender marker in some sign languages, when the location of a person term, man or woman, has been preserved also in the terms father or mother. In his data he found iconicity in kinship terms, but it was not similar in all sign languages. The iconicity was motivated by both universal and culture-specific properties. Thus, typological variation has been shown to exist among sign languages with respect to kinship terms. 
2.2. Kinship terms in FinSL

The semantic domain of kinship in signed languages primarily includes lexical kinship terms. Here we will analyse the terms for both core and noncore family members in FinSL.

\subsubsection{Core family terms}

Core family terms include those for parents, children, brothers and sisters, and spouses. There is a gender distinction in some signs referring to core family terms: MOTHER/FATHER (Figure 1), FEMALE^ ${ }^{\wedge}$ FFSPRING for

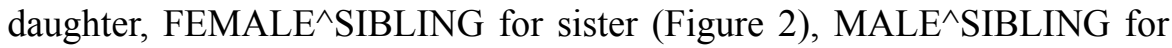
brother, MALE^SPOUSE for husband (Figure 3) and FEMALE^SPOUSE for wife (Figure 4). From this we also see that the terms MOTHER and FATHER are single signs but the terms for daughter, sister and brother, wife and husband are compounds.
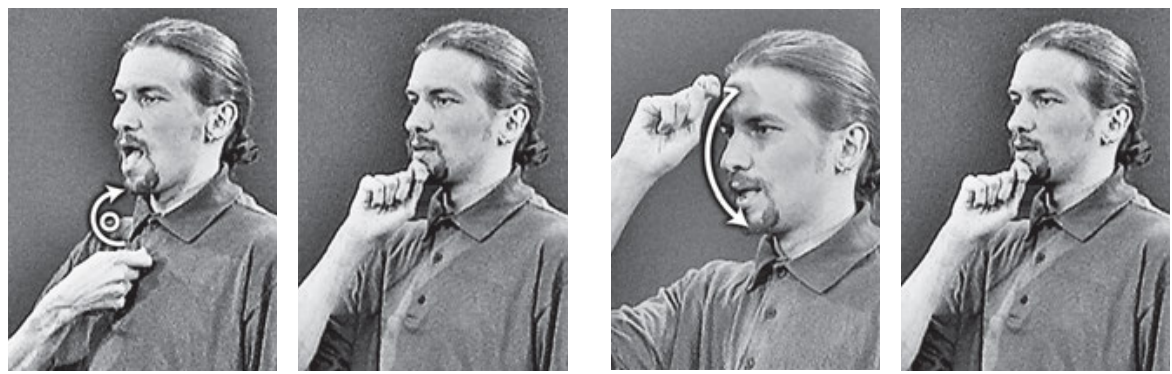

Figure 1. MOTHER, FATHER

(The images in the figures 1-4, 6-7, and 9-13 are from Malm 1998.)
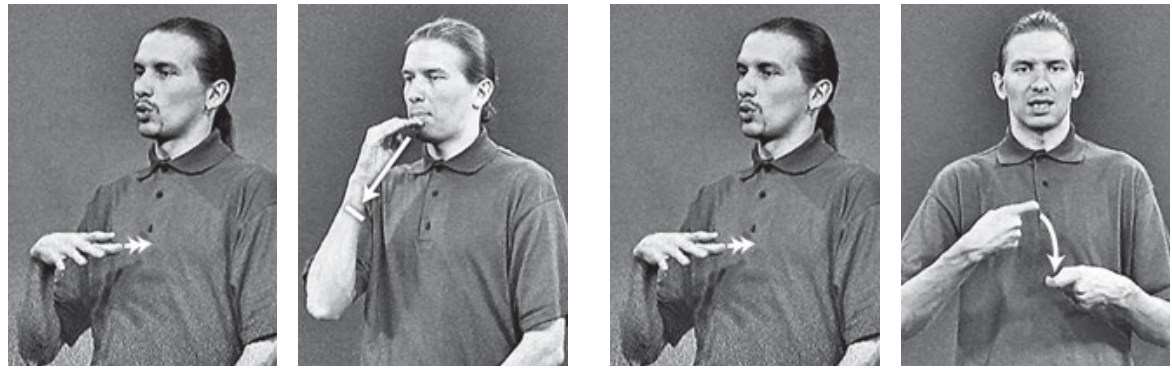

Figure 2. FEMALE ${ }^{\wedge} \mathrm{OFFSPRING}_{\text {FEMALE}}{ }^{\mathrm{S}} \mathrm{SIBLING}$ 

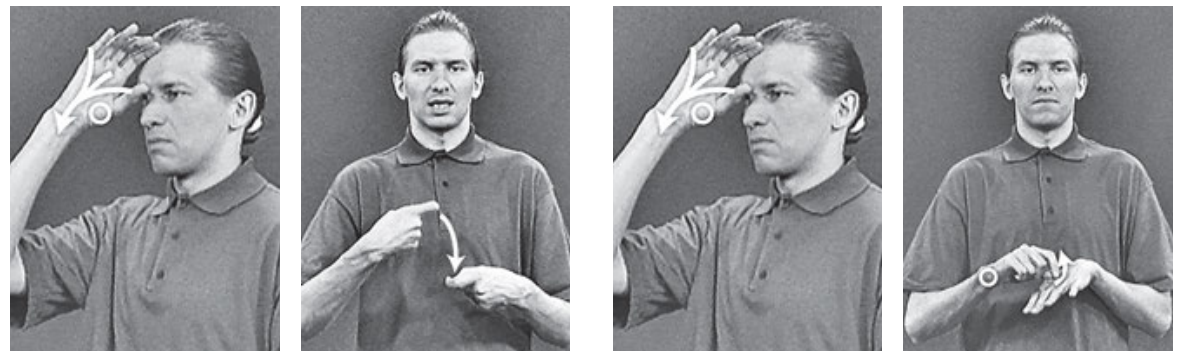

Figure 3. $\mathrm{MALE}^{\wedge} \mathrm{SIBLING}, \mathrm{MALE}^{\wedge} \mathrm{SPOUSE}$
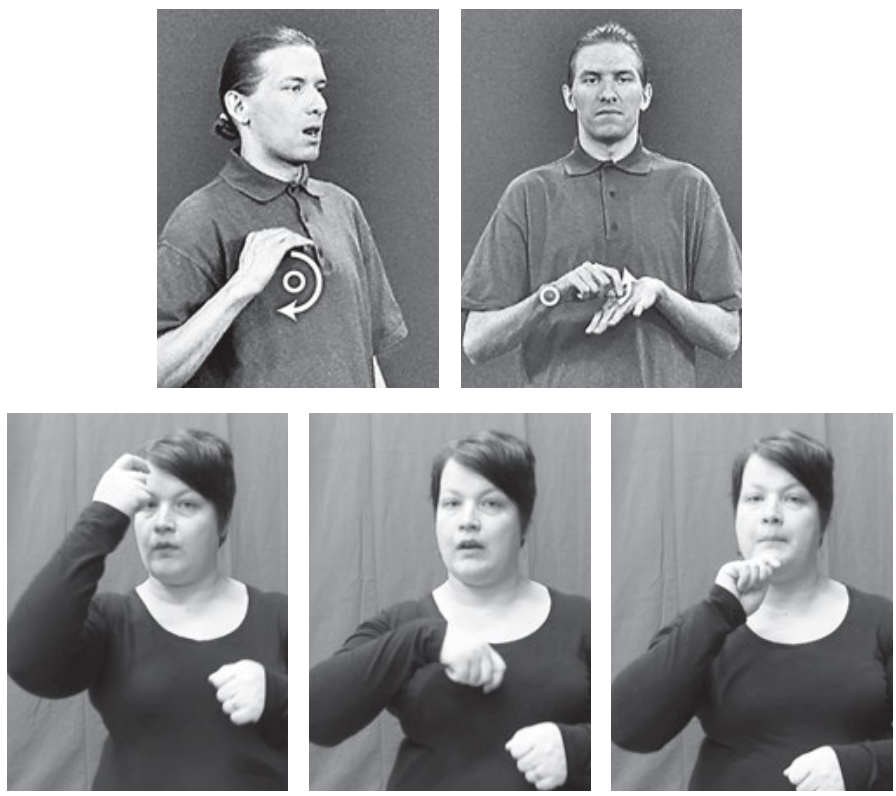

Figure 4. FEMALE^SPOUSE, FATHER ${ }^{\wedge}$ MOTHER

In addition to the gendered signs, there are also non-gendered signs: FATHER ${ }^{\wedge}$ MOTHER (Figure 4) for parents, a compound, and SIBLING, OFFSPRING and SPOUSE, which are single signs. Structurally the terms can vary, as seen above: some are individual signs, but others are compounds. In this context we include in the concept of a compound twosign (or three-sign) constructions that undergo phonological processes but also those that do not. As Velupillai (2012) puts it: compounds are two words (here signs) that constitute its own phonological unit wether they are written together or not. 
In core family terms FinSL makes a lexical distinction between older and younger children (OLDER ${ }^{\wedge}$ OFFSPRING and YOUNGER ${ }^{\wedge}$ OFFSPRING) as well as older and younger brothers and sisters (OLDER ${ }^{\wedge}$ SIBLING and YOUNGER^SIBLING) (Figure 5). Because FEMALE^OFFSPRING, MALE $^{\wedge}$ SIBLING and FEMALE $^{\wedge}$ SIBLING are already compounds, the age distinction is made by longer constructions, e.g. TALL+FEMALE^SIBLING, for older sister, not by a compound sign.
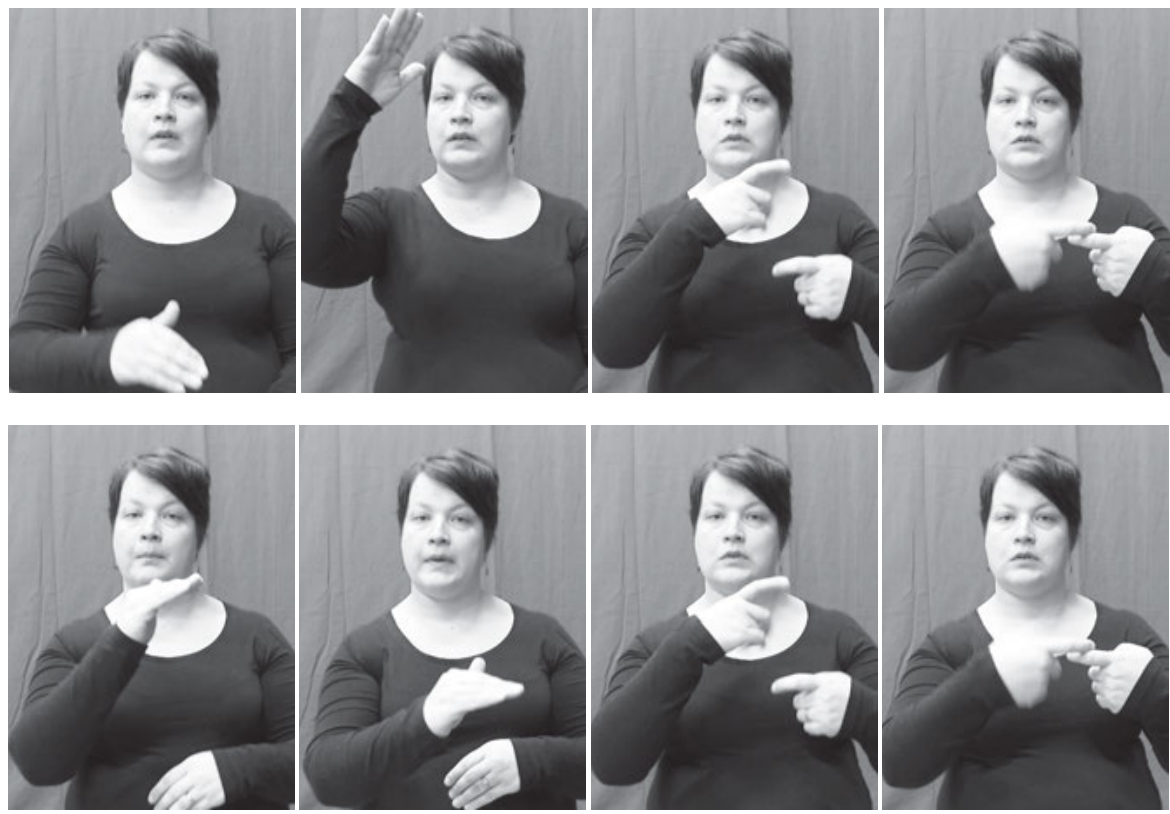

Figure 5. OLDER^SIBLING, YOUNGER^SIBLING

\subsubsection{Non-core family terms}

Non-core family members can be either individual signs, GRANDPAa and GRANDPAb, GRANDMA, AUNT, UNCLE, COUSIN, FIANCÉ (Figure 6), or compounds, $\mathrm{CHILD}^{\wedge} \mathrm{CHILD} 2$, FEMALE-FIANCÉ (Figure 7). The term GRANDPARENTS is composed of a compound including three parts $\mathrm{BIG}^{\wedge} \mathrm{FATHER}^{\wedge}$ MOTHER (Figure 8). The sign for grandchild has the repetitive form CHILD1 ${ }^{\wedge} \mathrm{CHILD} 2$, in which the locations of the repeated forms follow the same time-line as the sign for generation. The gender of maternal and paternal grandparents and the distinction between them are expressed in compounds MOTHER+MOTHER (Figure 9) for maternal grandmother, 
MOTHER+FATHER for maternal grandfather, FATHER+FATHER for paternal grandfather, and FATHER+MOTHER for paternal grandmother. In these signs the single signs are articulated fully, FATHER+MOTHER (Figure 9) unlike in the term PARENTS. Non-core family members show gender distinction only in the terms GRANDPA, GRANDMA, AUNT, UNCLE, FEMALE^FIANCÉ.
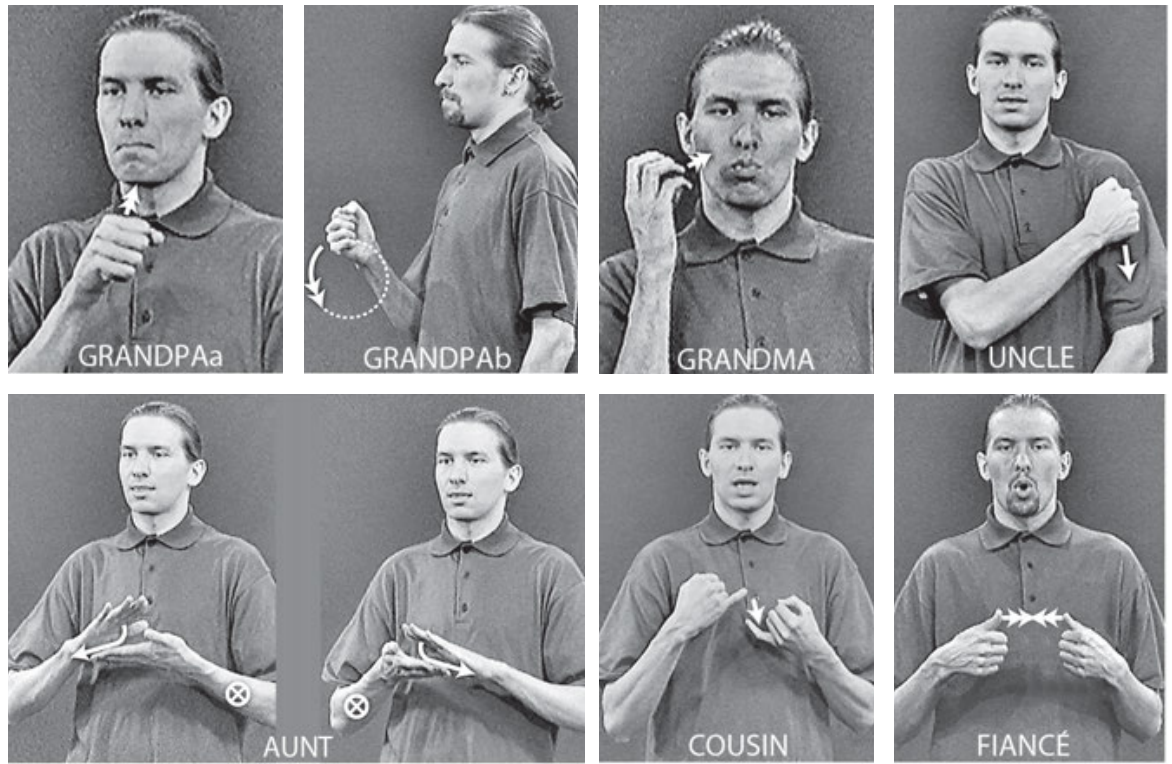

Figure 6. GRANDPAa, GRANDPAb, GRANDMA, UNCLE, AUNT, COUSIN, FIANCÉ
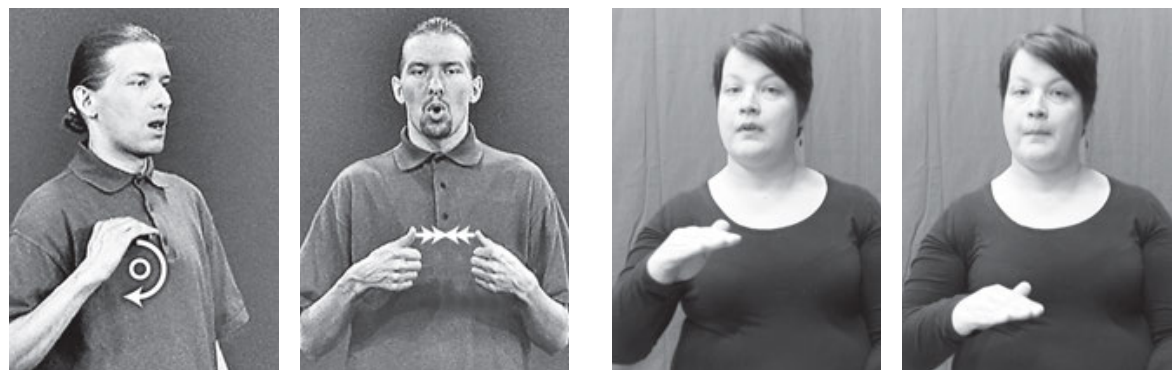

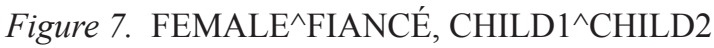


A typological look at kinship terms, colour terms and numbers in FinSL 131
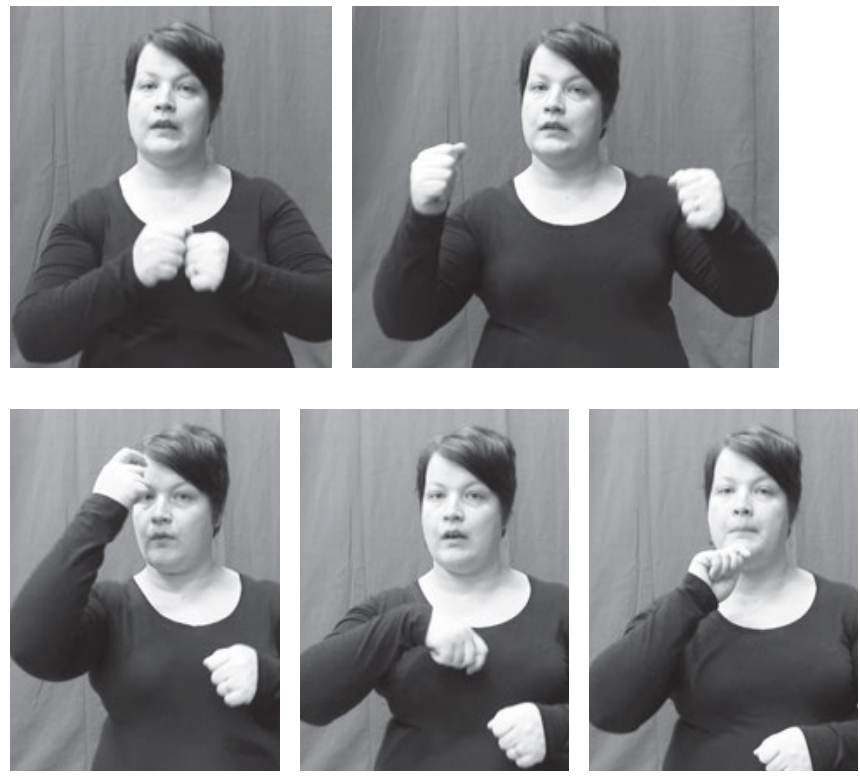

Figure 8. BIG $^{\wedge}$ FATHER ${ }^{\wedge}$ MOTHER
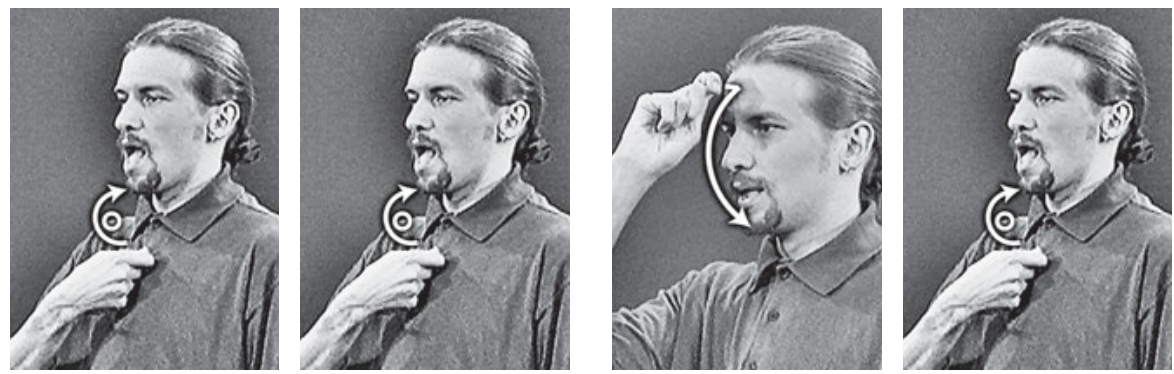

Figure 9. MOTHER+MOTHER, FATHER+MOTHER

\subsubsection{Terms for blended families}

In FinSL some of the single signs for the members of blended families (formed through marriage), such as FATHER-IN-LAW and MOTHERIN-LAW, have gender distinction. These signs are also used to refer to GRANPA and GRANDMA (Figure 6). Such family relations as step-mother, 
step-father, step-daughter and step-son are expressed as compounds, HALF`MOTHER, HALF^FATHER, HALF^FEMALE^OFFSPRING, HALF $^{\wedge}$ OFFSPRING, HALF $^{\wedge}$ SIBLING, HALF $^{\wedge}$ FEMALE$^{\wedge}$ SIBLING and $\mathrm{HALF}^{\wedge} \mathrm{MALE}^{\wedge} \mathrm{SIBLING}$ (Figure 10).
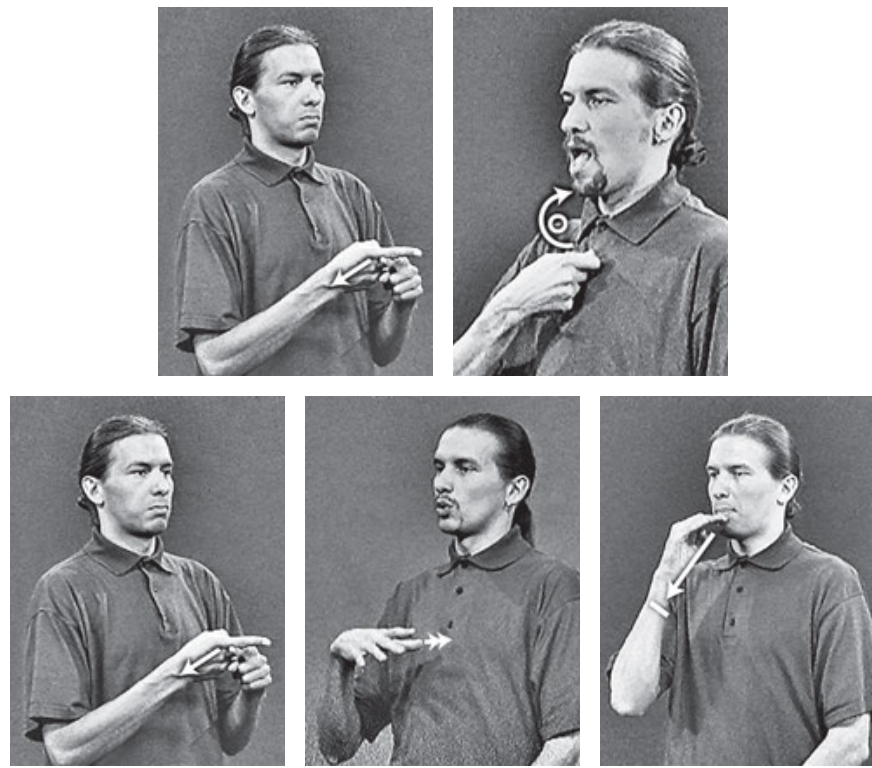

Figure 10. HALF $^{\wedge}$ MOTHER, HALF$^{\wedge}$ FEMALE$^{\wedge}$ SIBLING

Structurally the kinship terms are formed mostly on the area of the head (forehead, chin and cheek), but they may also be formed on the chest, in neutral space, and on the non-dominant hand. In many signs the location changes: the sign MOTHER starts at the chest and ends at the chin; the sign FATHER starts at the forehead and ends at the chin; and the sign PARENTS starts at the forehead, goes to the chest and ends at the chin. In coumpounds it is common for the location to change. The forehead location is typical of signs denoting the male gender and the chest is typical of signs denoting the female gender. In these cases the location carries semantic information (cf. Wilkinson 2009). Neutral space is the location for the signs SIBLING, COUSIN, AUNT and FIANCÉ. The sign UNCLE is articulated on the upper arm of the non-dominat hand and the sign SPOUSE on the back of the hand (putting a ring on the ring finger). 


\subsubsection{Relation to other languages}

Wilkinson (2009) found iconicity in his research on 40 sign languages but iconicity appeared in different ways in different languages. In FinSL, kinship terms also showed some iconicity e.g. in the locations of the terms denoting female and male genders, in the location, movement and handshape of the sign SPOUSE (putting a ring on the finger) and in the direction of the movement when referring to older or younger brothers or sisters. In FinSL, kinship terms do not include any initialisation signs, or loans from the written language.

Congruence on the semantic level between FinSL and Finnish is clear. The kinship system is almost the same in Finnish and in FinSL concerning the distincted categories, although Finnish has more kinship terms. For example, Finnish also makes a distinction between maternal and paternal uncle, 'eno' and 'setä', when FinSL does not. Moreover, Finnish has terms for husband's sister or brother's wife ('käly') and husband's brother or sister's husband ('lanko'), which are not found in FinSL. However, for the most part the kinship terminology is similar, which shows the languages' similar cultural base and contact between FinSL and the majority language, Finnish.

To summarise, FinSL has kinship terms for the core and non-cor as well as for blended family members. There is also gender distinction for most of the terms. Structurally the terms can be signle signs or combounds. Some iconicity is seen in the articulation places of the terms. The system of kinship terms in FinSL resembles that of Finnish language.

In the next section we move to colour terms. First we present the typological studies done in spoken language and the research what is so far done in sign languages. After that the colour terms in FinSL are discussed.

\section{Colour terms}

\subsection{Typological background}

Colour is the cultural classification of certain physical stimuli (Conklin 1973). An important landmark in typological studies of colour terms in different languages was Berlin \& Kay's investigation (1969), in which they proposed a hypothesis of basic colour terms (BCTs) and the developmental 
order in which they appear in languages. The researchers investigated 98 languages or dialects. They defined a BCT as follows:

1. a mono-lexemic term whose meaning is not predictable from the meaning of its parts

2. a term whose signification is not included in that of any other colour term

3. a term whose application is not restricted to a narrow class of objects

4. a term that is psychologically salient for subjects (having both a tendency to occur at the beginning of elicited lists of colour terms, and stability of reference across subjects and occasions of use in the idiolects of all subjects).

The researchers showed that the world's languages have from two to eleven basic colour terms, and concluded that they developed in a fixed order and in seven stages:

$\begin{array}{ll}\text { I } & \text { black and white (2) } \\ \text { II } & \text { red (3) } \\ \text { II } & \text { green or yellow (4) } \\ \text { IV } & \text { yellow or green (5) } \\ \text { V } & \text { blue (6) } \\ \text { VI } & \text { brown (7) } \\ \text { VII } & \text { purple, pink, orange, grey (8-11). }\end{array}$

Berlin \& Kay's research (1969) has been criticised at times but it has also inspired a lot of studies that have sought to test their hypothesis in spoken languages (see e.g. Conklin 1973, Dowman 2007, Koski 1989, Kivinen 2007), and recently also in signed languages (Woodward 1989, Nonaka 2004, Hollman \& Sutrop 2010). The research done on several languages has resulted in revisions of the original model. Kay \& Maffi (1999) revised the model using the empirical and theoretical considerations that emerged from several studies. They recognised three kinds of universal colour categories (Kay \& Maffi 1999):

1. primary colour categories (black, white, red, yellow, green, blue)

2. composite (disjunctive) colour categories (fuzzy unions e.g. grue, black/green/blue, white/red/yellow, black/blue, red/yellow, yellow/ green/blue, yellow/green)

3. derived (intersective) colour categories, which are experienced as mixtures of the primaries. 
There has, however, been little research into colour terms in signed languages. Woodward (1989) investigated 10 sign language from 7 different sign language groups: the French SL group (FSL, ASL), British SL group (Auslan), Japanese SL group (JSL, Taiwanese SL), Chinese SL group (CSL, Hong Kong SL), indigenous (Providence Island SL), and unknown (Saudi Arabian SL). He found that these sign languages follow the universal patterns shown in the colour terminology in spoken languages, and that they are characteristic of human language and independent of the channel of the language of expression and reception.

Nonaka (2004) investigated Ban Khor sign language, an indigenous signed language that is one of the many signed languages used in Taiwan, and is now in danger of extinction. She found that Ban Khor SL is a three-colourterm language, consistent with Berlin \& Kay's (1969) hypothesis, since the colours belong to the two first phases of the BCT model, white, black and red. Other colours are expressed by pointing to an object in the environment that is the same colour; if there is no such colour in the environment, then code switching to Taiwanese SL is used. These three colours originate in pointings to the hair for black, to teeth for white, and to the lips for red, but the signs are now lexicalised. Taiwanese sign language (TSL) has a multiterm colour lexicon in which the three basic colour terms refer to body parts, an eyebrow for 'black', an upper arm for 'white' and the lips for 'red'. The other colour terms, e.g. 'pink', 'purple', 'yellow', are initialised signs that use the fingerspelled letter from the Thai manual alphabet. (Nonaka 2004.)

Nyst (2007) studied Adamorobe sign language in Ghana and found that there are methodological problems in defining basic colour terms in sign languages. Defining the basic colours depends on how strictly the criteria of Berlin and Kay (1969) are applied. For example, in Adamorobe SL the three basic colours are signed with the same manual sign (a generic sign) but the mouthing distinguishes the meaning. Yellow and green are based on the entity bearing the same colour.

The basic colour terms have also been investigated in Estonian sign language (ESL) (Hollman \& Sutrop 2010). Here too the researchers applied Berlin and Kay's theory of basic colour terms in their study. They used a list test and a colour naming test in their study and tested all the participants $(\mathrm{N}=50)$ with the Colour Vision Test (Fletcher 1980). The results showed several colour expressions. The researchers then carried out a salience analysis created by Davies and Corpett (1995) and further developed by Sutrop (2000). From this the researchers concluded that ESL is in Stage VII (Berlin \& Kay 1969) since the basic colour terms are BLACK, WHITE, RED, YELLOW, GREEN, BLUE, GRAY, BROWN and PINK/PURPLE. 
Other means of expressing colours are, for example, adding the signs DARK or LIGHT to the colour term (BROWN LIGHT, RED DARK) and fingerspelling (r-o-s-a, b-e-e-ž.)

\subsection{Colour terms in FinSL}

As we saw in the previous section, the forms of colour terms in signed languages are often iconic or motivated. In many signed languages, body parts or objects in the environments are indicated to refer to colours. Signs may also be motivated by a link to the written language, for instance in initialised signs where the fingerspelled first letter of the written word for a colour is used.

\subsubsection{The basic colour terms in FinSL}

In FinSL there is an abstract sign COLOUR as a hypernym for the separate colour signs (Figure 11.). Classified according to Berlin \& Kay's (1969) basic
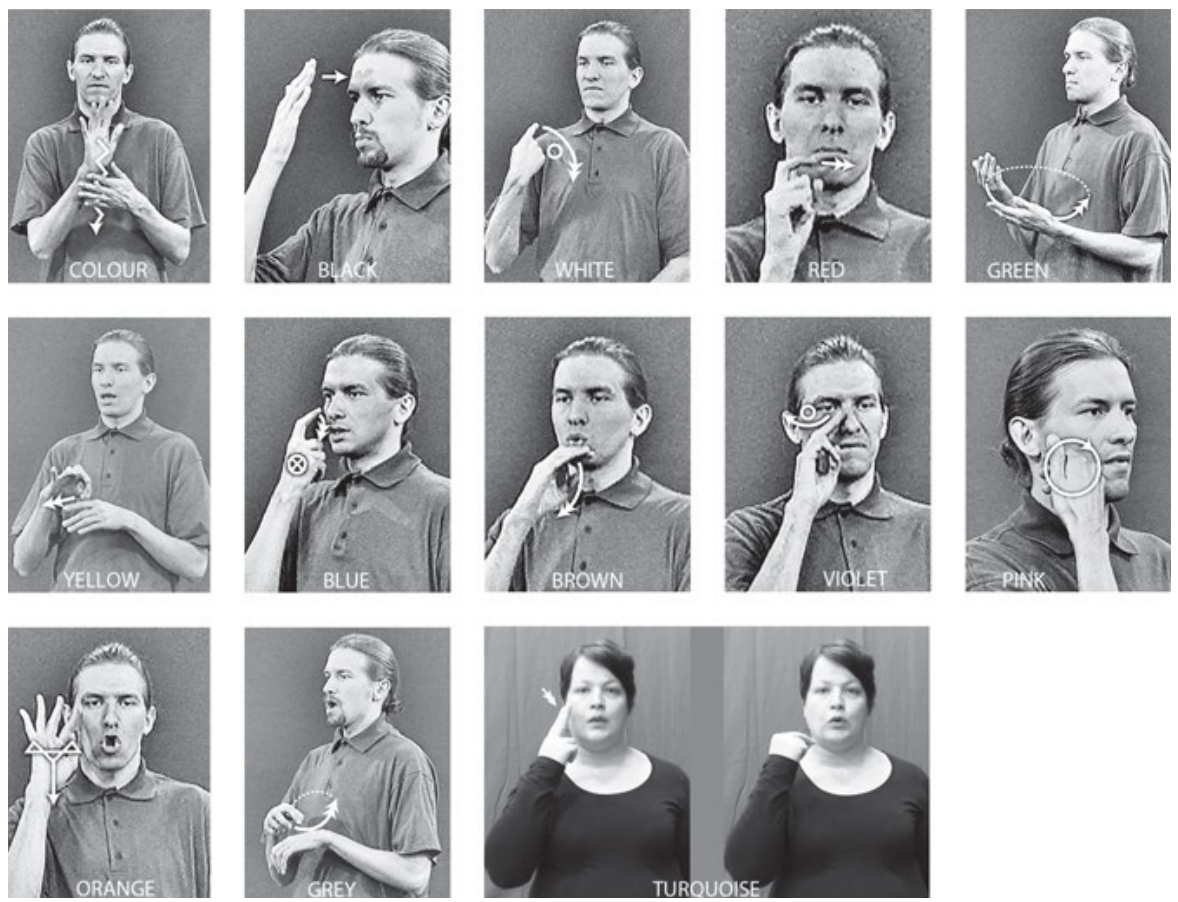

Figure 11. COLOUR, BLACK, WHITE, RED, GREEN, YELLOW, BLUE, BROWN, VIOLET, PINK, ORANGE, GREY, TURQUOISE 
colour terms (BCT) model, FinSL has lexical signs for all the eleven colours, black, white, red, green, yellow, blue, brown, purple/violet, pink, orange, and grey (Figure 11), that are mentioned in the seven phases proposed by Berlin \& Kay. In addition to these terms, FinSL also has a sign TURQUOISE (Figure 11). The basic categorisation of the colour terms is similar to Finnish.

\subsubsection{Complex colour constructions}

In addition to the single basic colour terms, FinSL uses complex colour constructions. Single colour signs can also be combined sequentially with other signs, e.g. LIGHT+BROWN or DARK + BROWN (Figure 12). They can involve morphological modification of the manual (single) sign, e.g. !RED! for 'strong red' or SLIGHT-REDxx for a little bit red, 'slightly red' (Figure 12). In the first sign the movement is larger and faster, and in the second sign the movement is repeated and on a smaller scale than in the basic form. Colour signs can also be modified by additional facial expressions, e.g. !BLUE! for 'strong blue' and SLIGHT-BLUExx for 'slightly blue'. In the sign meaning 'strong blue' the eyes are squinted, and in the sign meaning 'slightly blue' the eyes are slightly squinted and the movement is very small and is repeated. In the sign !ORANGE! for 'strong orange'
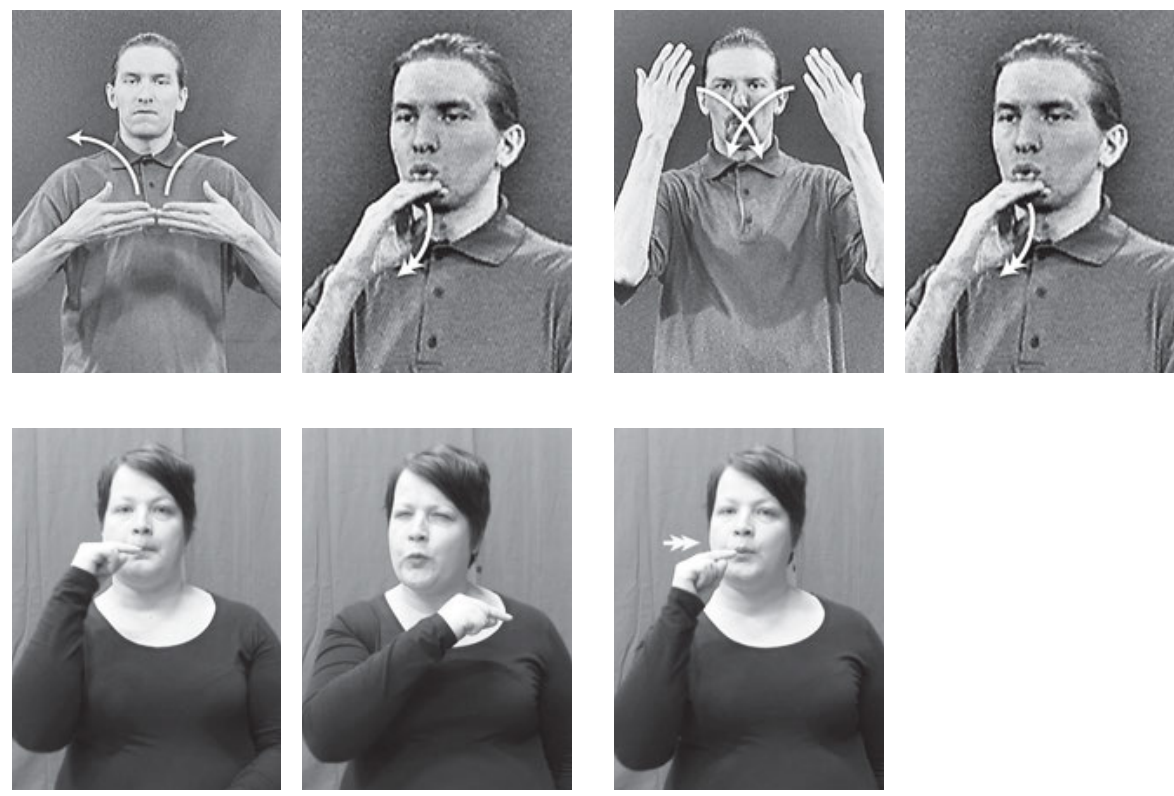

Figure 12. LIGHT+BROWN, DARK+BROWN, !RED!, SLIGHT-REDxx 
the movement is faster and more intensive and the mouth pattern is also stronger. As we can see, modification of the manual sign and facial modification often appear at the same time: the movement can be larger or smaller, repeated, and produced faster or slower. The facial modification involves narrow squinting of the eyes or movement of the mouth. Even the body position can be modified, as in the sign !YELLOW! for 'strong yellow'. Only signs that are articulated in neutral space can be spatially modified, i.e. signed nearer the referent with which the colour is associated. However, most of the colour signs in FinSL are articulated on the body and do not include special modification.

\subsubsection{The semantic relations of the colour terms to objects}

The colour terms in FinSL are semantically related to objects. The sign BLACK is articulated on the face, the palm put on the eye, referring to darkness when the eyes are covered. The sign WHITE is articulated near the neck, indicating a white collar. The sign RED is signed under the lips, getting its motivation from the redness of lips. FinSL has two signs for green: GREENa resembles the sign for poison, and GREENb refers to the sign for hay. The sign YELLOW refers to the lighting of matches. For blue FinSL again has two signs: BLUEa, which points to the eye (most Finns have blue eyes) and BLUEb, which points with a flat hand to the sky (Figure 13). The sign BROWN is articulated by touching the chin, so the motivation for this may be a beard. The sign VIOLET is articulated under the eye, referring perhaps to the "black" rings under the eyes that can be seen on some people's faces. The sign PINK is signed on the cheek, referring to the light red colour of the cheek. The sign GREY is articulated on the forearm in the same place as the sign sheep, so associated with sheep's greyish wool.

The only basic colour which has contact-induced motivation from Finnish is ORANGEa, (Figure 13) orange. It is an initialised sign using the $\mathrm{O}$ handshape. The articulation place is the same as in the sign YELLOW. There is also two other signs for orange, ORANGEb and ORANGEc (Figure 13) but the motivation for these signs is unclear. Nowadays they seem to be abstract signs. As we have seen above, for several basic colours there are (at least) two signs in FinSL. All these variants are still in use today.

Complex constructions of colours, including modification of the manual colour sign, facial modification and the modification of the body position, indicate saturation, changes in the colour spectrum, and hedging, softening the meaning. Saturation means the intensity of the colour, e.g. a bright colour is signed with a larger and faster movement. The colour spectrum 

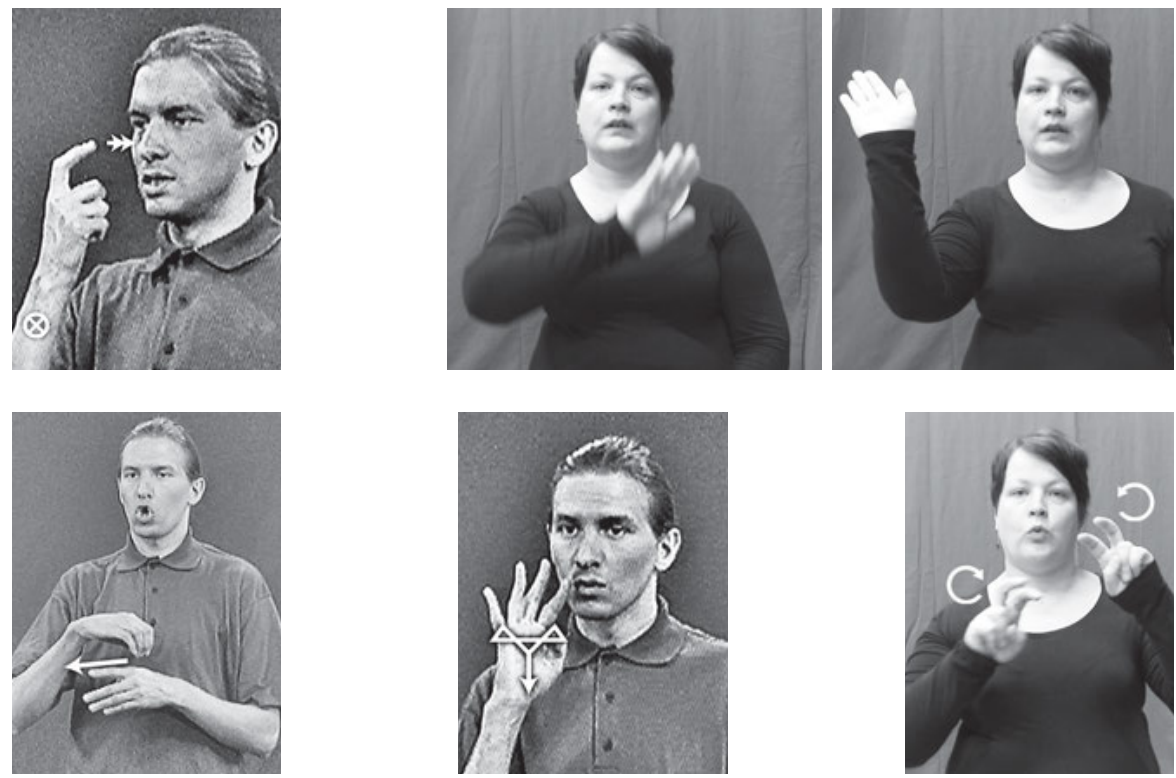

Figure 13. BLUEa, BLUEb, ORANGEa, ORANGEb, ORANGEc

can be varied by combining the sign LIGHT or DARK with the colour signs. Softening the colour expression, e.g. SLIGHT-REDxx, is produced by shortening and repeating the movement. Sometimes the different signs for the same colour can be used to specify the exact colour, e.g. SININENb, 'blue' for referring to sky blue, although the sign is also used as a general sign for blue.

\subsubsection{The relationship between FinSL and Finnish colour terms}

The relationship between FinSL and Finnish is close in the basic colour terms. Koski (1983) studied colour terms in Finnish and languages related to it. He also adapted Berlin \& Kay's (1969) model in his etymological research. He included eight terms in the basic colour terms of Finnish: valkoinen (valkea) 'white', musta 'black', sininen 'blue', punainen 'red', keltainen 'yellow', vihreä 'green', harmaa 'grey' and ruskea 'brown'. During the 30 years since his study was conducted, the terms violetti 'violet', oranssi 'orange' and vaaleanpunainen 'pink' have stabilised their status in the lexicon of Finnish speakers. In Finnish the term 'turkoosi' is also used for the colour turquoise. Also where modifications of the spectrum are concerned, Finnish and FinSL use the same kinds of combinations of words, 'vaalea' and the 
colour word in Finnish and the sign VAALEA and a colour sign in FinSL. Finnish, like FinSL, has rich morphological means of word formation (derivation) but the forms used are naturally different. The contact between the two languages is evident in the fact that the same basic colour terms are now seen in both languages. Although FinSL is a young language, it has a wide colour vocabulary.

\subsubsection{Relation to universal colour categories}

Looking at colour expressions from the viewpoint of the three universal colour categories proposed by Kay \& Maffi (1999), FinSL has lexical signs for the primary colour categories (black, white, red, yellow, green, blue etc). For the derived (intersective) colour categories that are experienced as mixtures of the primaries FinSL uses constructions composed of several signs, e.g. RED+ORANGE+BLEND (Figure 14).
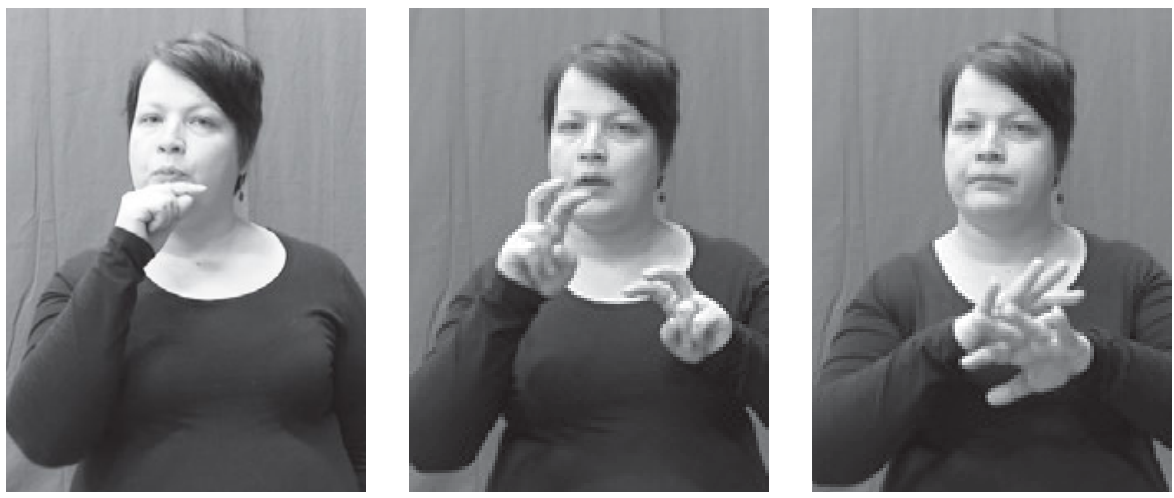

Figure 14. RED ORANGE BLEND

If we compare the colour categorisation in FinSL with that in the other sign languages that have been studied, we see that colour categorisation in FinSL quite closely resembles that used in Estonian Sign Language (ESL) (Hollman \& Sutrop 2010). In ESL there are also lexical signs for eleven basic colours. For colour spectrum variation ESL uses the sequential structures of the sign for 'light' or 'dark' and the colour signs. In both FinSL and ESL it is also possible to fingerspell the name of the colour if there is no lexical sign, e.g. b-e-i-g-e.

To summarise, FinSL has 11 basic colour terms described by Berlin $\&$ Kay (1969) as well as a term for 'turquoise'. It also expresses derived (intersective) colour terms (cf. Kay \& Maffi 1999), e.g. RED+ORANGE+BLEND. 
The colour categorisation is similar to that of Finnish. FinSL uses also complex colour constructions: a colour term is combined with another sign (e.g. LIGHT-BROWN), or colour terms involve a morphological modification (e.g. !RED!, SLIGHT-BLUE). The colour terms in FinSL are also semantically related to objects: they are signed on the areas of a body part (e.g. RED signed near the lips) or refer other ways to objects (e.g. GREEN resembles the sign for 'hay'). It is also possible to fingerspell some colour which does not have a sign, e.g. b-e-i-g-e.

In the next section we discuss the number system of FinSL. First we introduce the typological background, after that we discuss the nominal number, cardinals and ordinals, and lastly numeral incorporation in FinSL.

\section{Number}

\subsection{Typological background}

Taking our last theme, number, every language has a way of referring to the quantity and order of objects, events etc, but number systems vary across languages. Comrie (2008) distinguishes four main types of arithmetic numeral bases in the world's languages: decimal, hybrid vigesimal-decimal, pure vigesimal, and extended body-part system. Of these, the vast majority of languages use the decimal system. The general structure of this system is $x 10+y$. This means that, for example, the number 32 is constructed by multiplying the basic cardinal number 3 by the base 10 and then adding the cardinal number 2 to the outcome.

Numbers are generally divided into cardinal and ordinal numbers. Cardinal numbers are used in the attributive quantification of nouns whereas ordinal numbers identify the position a given member of a set occupies relative to other members of the same set (Stolz and Veselinova 2008). In most languages, ordinal numbers are morphologically or syntactically connected to cardinal numbers. For spoken languages that have ordinal numbers, Stolz and Veselinova (2008) have identified at least six patterns of how this connection may manifest itself: (i) the cardinal numbers may be used as ordinals without any modification; (ii) cardinal and ordinal numbers are identical except for 'one' and 'first'; (iii) ordinal numerals are derived from cardinal numerals; (iv) all ordinal numerals are derived from cardinal numerals with two alternatives for 'first' (one of which is morphologically independent of 'one', i.e. suppletive); (v) ordinal numbers from 'two' upwards are derived from cardinal numbers, 'first' being suppletive; and (vi) 'first' and a small set of consecutive higher ordinal numbers are suppletive. 
In studies of spoken languages, numerals have often been approached from the perspective of their grammatical class: the goal has been the classification of numerals into grammatical categories such as adjective or substantive. This has not always been easy (e.g. Comrie 1981). With sign languages, the main approach to numbers has been different. Instead of approaching numerals as a grammatical category, the main aim - obviously motivated by the manual modality - has been the description of number systems. Up-todate descriptions have been provided for several sign languages, including Catalan Sign Language (Fuentes and Tolchinsky 2004) and Finnish Sign Language (Jantunen and Savolainen 2002). Numbers in sign languages have also been investigated from the historical and sociolinguistic perspectives (e.g. Fischer 1996; McKee, McKee and Major 2011). Such studies have shown that number systems vary considerably, for example, according to the signers' age.

Numeral incorporation - the incorporation of cardinal numbers into lexical paradigms by producing the numerical value simultaneously with a lexical element (Sakara, de Vos and Zeshan 2012) - has been the most discussed number-related grammatical issue in sign languages. In sign languages, numeral incorporation occurs in a variety of semantic domains, the most typical one perhaps being that of temporal expressions. Liddell's (1996) bound-root analysis of the phenomenon has been widely cited. Liddell's analysis also forms the underlying analytical basis in the discussion in this paper of numeral incorporation in Finnish Sign Language (see Section 4.2).

\subsection{Nominal number in FinSL}

In this section we describe cardinal (4.2.1) and ordinal numbers (4.2.2) as well as numeral incorporation (4.2.3) in the lexicon of Finnish Sign Language (FinSL). Mention is made of notable overlaps with Finnish, as well as points of difference.

\subsubsection{Cardinal numbers}

The FinSL cardinal number system is over 160 years old. It was devised in the middle of the 19th century by the deaf founder of Finnish education for the deaf, Carl Oscar Malm. The numbers 0-5 were borrowed directly from (the old) Swedish Sign Language (SSL), the language Malm had learnt during his stay in Stockholm's school for the deaf. For numbers from 6 onwards (up to one thousand) Malm introduced a more original strategy, the 
main characteristic of which was one-handedness (Hirn 1909). Today, all the numbers in FinSL are one-handed.

The FinSL number system is based on 10, that is, FinSL uses the decimal system (Comrie 2008), as does the surrounding Finnish language.

\section{Zero}

The FinSL sign meaning 'zero' is articulated on the level of the chest with the O-hand shape, the palm facing the contralateral side. The sign may be produced either as a hold or with a short straight (epenthetic) movement forwards (Jantunen and Savolainen 2002). The hold form is used in sequences, whereas the form with the movement usually occurs as an isolated sign (Jantunen and Takkinen 2010). However, also the hold form may be used as an isolated sign.

\section{Numbers $1-10$}

FinSL numbers 1-9 are shown in Figure 15. The number 1 is signed with an upwards pointing extended index finger (palm facing the signer on the
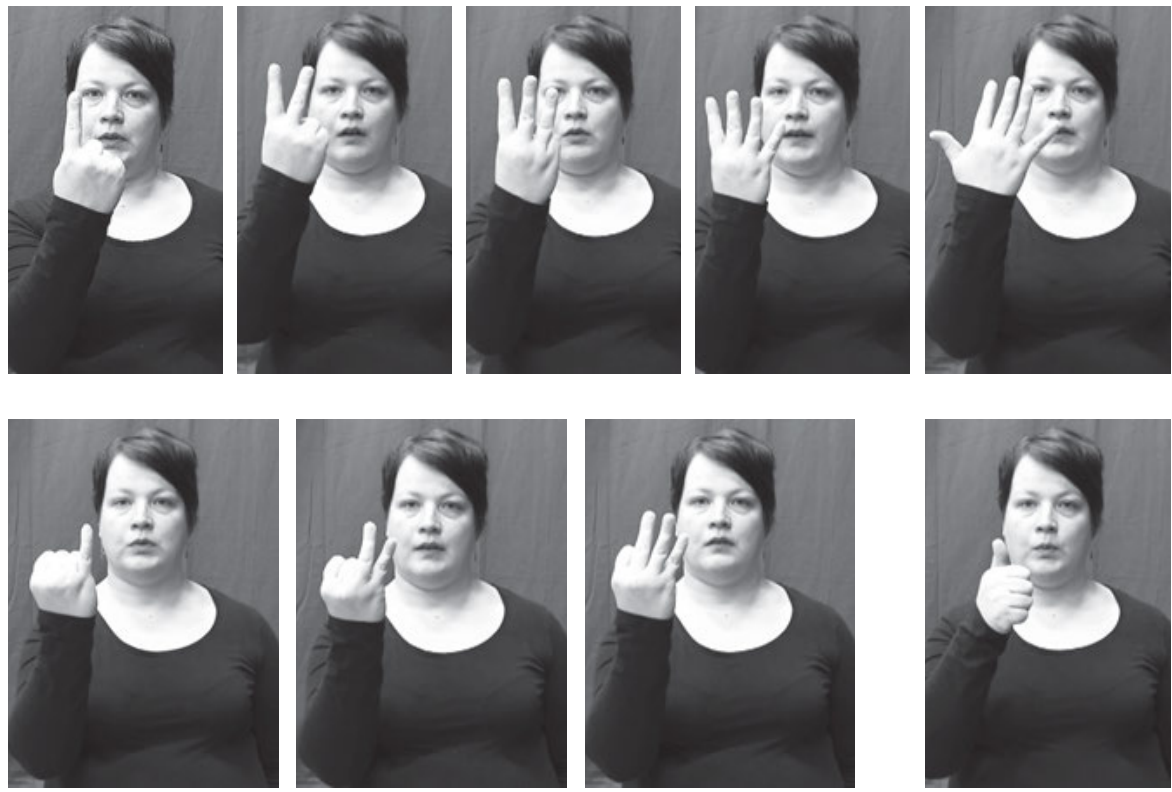

Figure 15. FinSL numbers 1-5 (upper row), 6-8 (bottom row left) and 9 (bottom row right). The number 9 is produced by oscillating the thumb-up hand shape from the wrist and foremarm. 
level of the chest; this is the standard palm orientation and place for cardinal numbers in FinSL, unless otherwise noted), and then extending and spreading the middle, ring, and little fingers produces numbers 2, 3, and 4, respectively. The number 5 is produced with all the fingers extended and spread. For the numbers $6-8$, the finger count is begun anew from the ulnar side of the hand: the number 6 is associated with an extended little finger, 7 with the extended and spread little and ring fingers, and 8 with the extended and spread little, ring, and middle fingers. Like the sign for 0 , so too the signs for 1-8 may be articulated either as holds or with a short forwards-directed (epenthetic) movement (Jantunen and Savolainen 2002).

The sign for 9 is signed by oscillating the humb-up hand shape from the wrist and forearm. Historically, the oscillation is considered to be a late addition to the structure of the sign although the extended upwards-pointing thumb has signalled the number 9 since the time of Malm (Jantunen 2001).

FinSL has independent lexemes for the names of the numbers 1-9 (Jantunen and Savolainen 2002). In these lexemes, the finger configuration is the same as in the corresponding basic number sign but the palm orientation is reversed (i.e. the palm faces mostly away from the signer; also, in the name for the number 9 , the thumb points to the contralateral side, not upwards) and the hand oscillates from the elbow joint either diagonally or vertically. The existence of name signs for numbers in FinSL is considered to be partially motivated by Finnish, which distinguishes between the words for the numbers as such (e.g. $y k s i$ ' 1 ') and their names (e.g. ykkönen 'the name of number 1'). There are no name signs in FinSL for numbers higher than 9.

The number 10 has two main variants, displayed in Figure 16. In TEN-A, the hand shape is the extended index finger (as in 1) which at the beginning of the sign points upwards (palm facing the contralateral side) and at the end, after the ulnar flexion of the wrist, is directed forwards. In TEN-B, the hand shape is also the extended index finger but this time it is directed to the

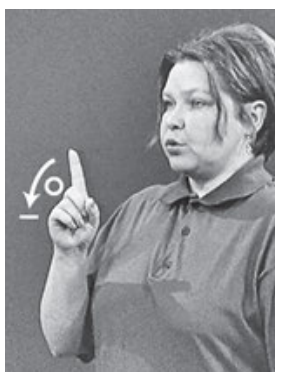

Figure 16. TEN-A

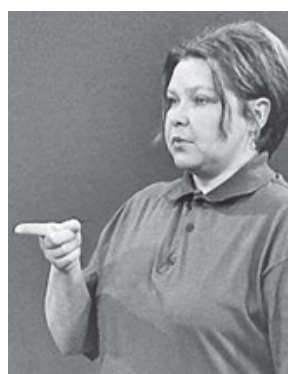

(left) and TEN-B

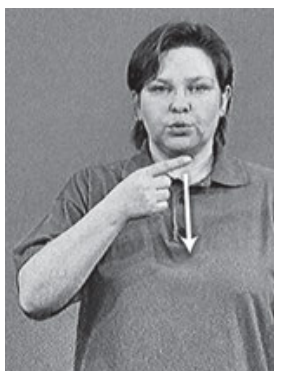

(right) Savolainen 2002).

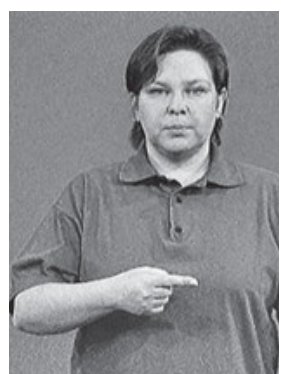

from Jantunen \& 
contralateral side, palm facing the signer. The movement of the sign TEN-B is a straight downwards pivot movement executed from the elbow joint.

The two variants for 10 differ in their use (Jantunen and Savolainen 2002). TEN-A is the more typical form, which is reflected also in the fact that it (but not TEN-B) may be converted into a plural ('tens') by rapidly repeating the wrist movement and, at the same time, moving the hand along a straight path to the ipsilateral side. TEN-B is used in situations that require special clarity (e.g. when signing for a camera or in front of an audience). However, historically, TEN-B corresponds to the form devised by Malm (Hirn 1909).

In terms of their iconicity, the numbers $0-5$ are iconic in that the sign 'zero' represents the round shape of the number 0 and the signs for $1-5$ correspond to the number of fingers extended. However, from 6 onwards the iconicity is lost. A contributory factor in this has obviously been the fact that the system for expressing numbers above 5 was devised by Malm with the deliberate intention of keeping the numbers expressible with only one hand.

\section{Cardinal numbers above 10}

\section{Simple multiples of ten}

The simple multiples of ten $(20,30$, etc. $)$ up to 80 are constructed by replacing the hand shape of the sign(s) for 10 with the hand shape of the numbers $2-8$. The strategy is the same with both of the variants of 10 . As was the case with TEN-A, the forms of the numbers $20,30,40,50,60,70$, and 80 produced from the wrist are considered to be more common today; they may, for example, be modified for plurality in the same way as TEN-A (Jantunen and Savolainen 2002).
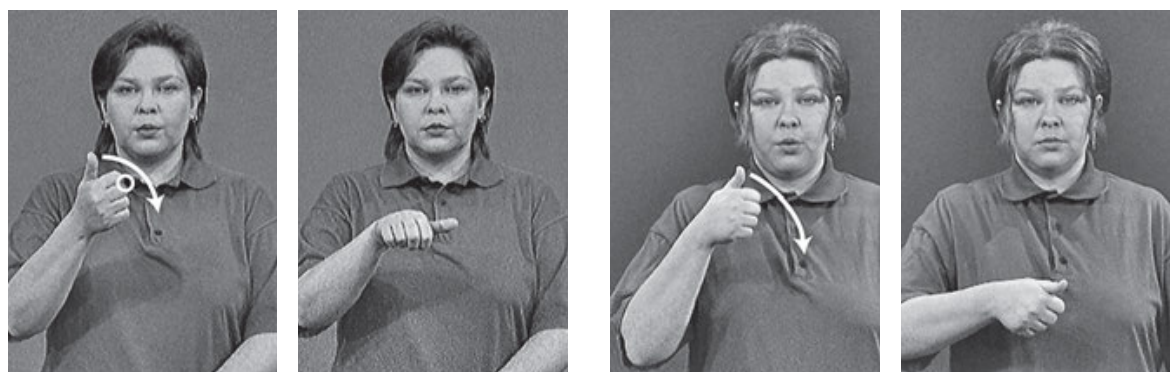

Figure 17. NINETY-A (left) and NINETY-B (right) (Images from Jantunen \& Savolainen 2002). 
The sign for 90 also has two variants (see Figure 17). The basic mechanism of constructing NINETY-A and NINETY-B is the same as with the other full tens. In contrast to the basic sign for 9, NINETY-A and NINETY-B do not contain the oscillating wrist movement. Neither of the two forms allows modification for plurality (Jantunen and Savolainen 2002).

\section{Numbers 11-99 excluding full tens}

All the numbers from 11 to 99 , excluding full tens, may be produced as shown in Figure 18. The strategy that is used to construct these numbers resembles sequential compounding, in which the two parts are further fused together with an orientation change and a hand shape change (except numbers $11,22,33,44,55,66,77,88$, and 99 , which only include an orientation change). Note that the first part of the signs, indicating full tens, is neither of the signs for 'ten' or their simple multiples ('twenty', 'thirty', etc.); rather, it is an independent form in which the movement resembles that in TEN-A (and its simple multiples) and the orientation that in TEN-B (and its simple multiples). The features of the hand shape are derived from the basic numbers.

There are several other strategies that may be used to form various subsets of the numbers 11-99. For example, for numbers 12-18, maybe even a more common strategy than that described above is that illustrated in Figure 19. Alternatively, the numbers 12-18 may also be formed with the strategy described in Figure 20. The main difference between the two strategies is that the first is based on supinating the wrist and the second on flexing the wrist radially.
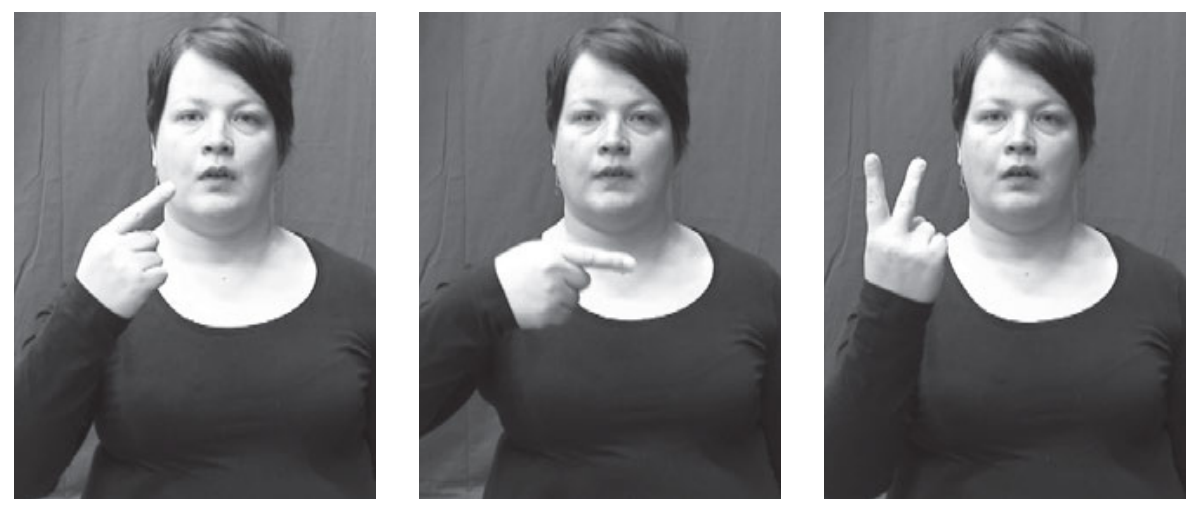

Figure 18. Number 12. 

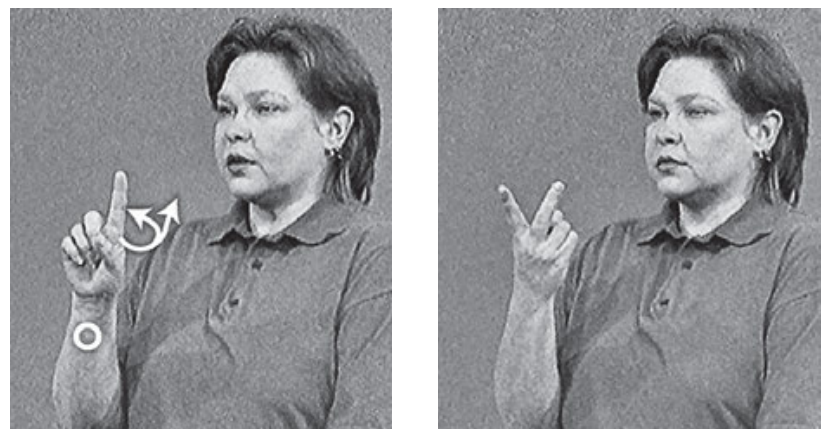

Figure 19. Number 12 constructed with a supinating wrist movement (Images from Jantunen \& Savolainen 2002).
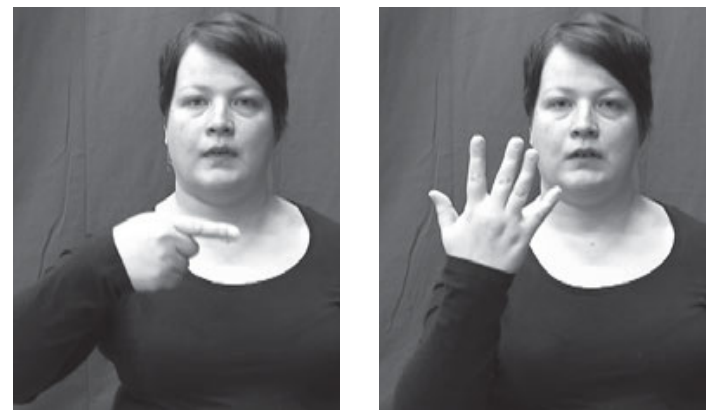

Figure 20. Number 15 constructed with a flexed wrist movement.

Also a very common strategy used to form number 19 is based on supinating the wrist. This is shown in Figure 21. Note that the latter part of the sequence indicating the number 9 is produced, again, without the oscillating wrist movement.
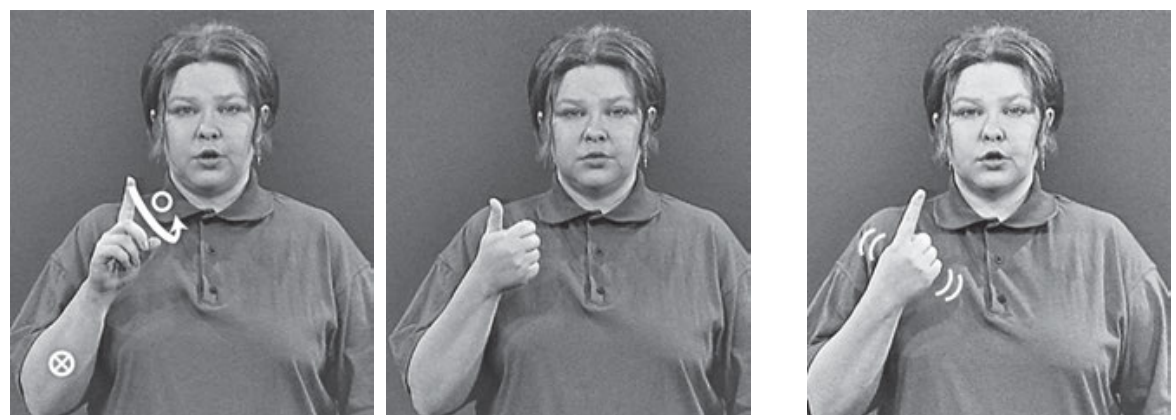

Figure 21. The sign for 19 produced by supinating the wrist (left) and the sign for 11 produced with an oscillating movement from the elbow (right) (Images from Jantunen \& Savolainen 2002). 
The number 11 may be produced with an oscillating movement from the elbow joint, as in Figure 21. Some FinSL users also use this paradigm to produce the numbers 22, 33, 44, 55, 66, 77, and 88 (Jantunen and Savolainen 2002).

\section{Hundreds}

FinSL indicates the numbers 100, 200, 300, 400, 500, 600, 700, 800, and 900 with a strategy shown in Figure 22. The base for the strategy, also historically (Hirn 1909), is the sign 100. All the subsequent full hundreds are formed by changing the hand shape features according to the base number system. The sign 100 may be modified for plurality ('hundreds') by rapidly iterating the sign and, at the same time, moving the hand along a straight path to the ipsilateral side (Jantunen and Savolainen 2002).
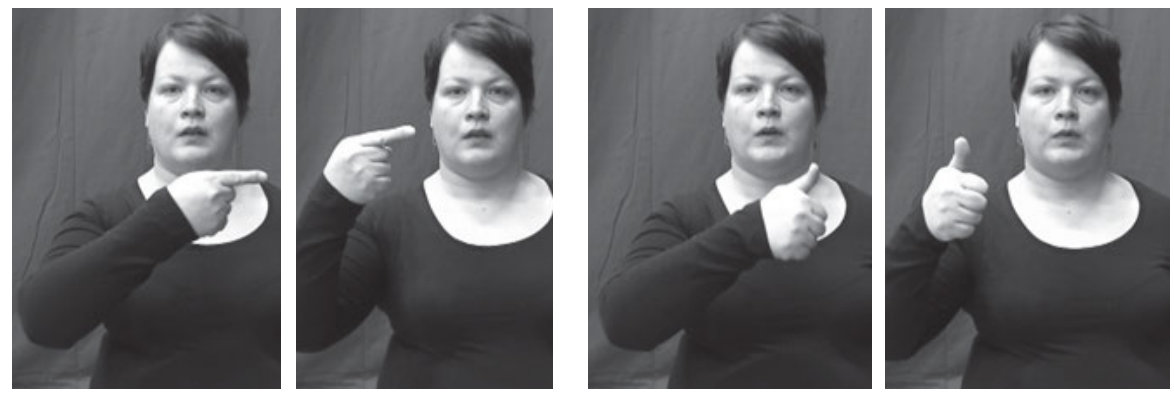

Figure 22. FinSL sign for 100 (left) and 900 (right).

\section{Thousands}

The most common way to sign the numbers $1000,2000,3000,4000,5000$, $6000,7000,8000$, and 9000 is illustrated in Figure 23. As with full hundreds,
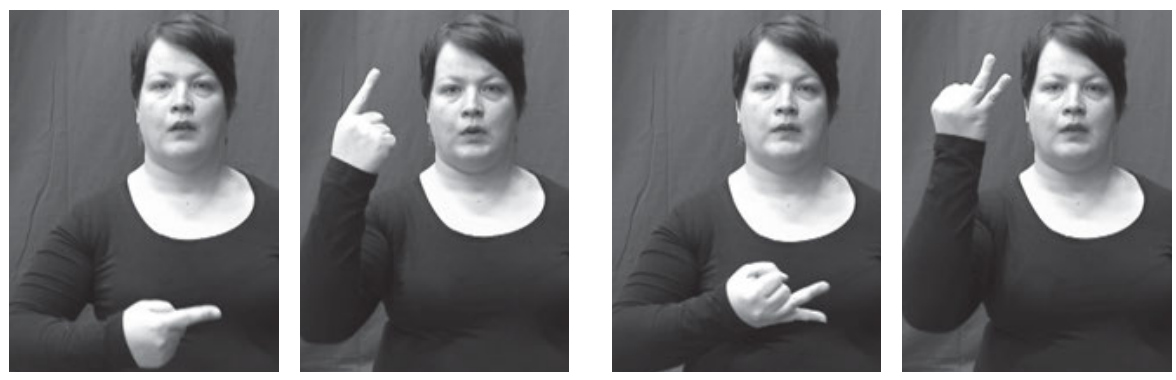

Figure 23. FinSL signs for 1000 (left) and 7000 (right). 
the base for the strategy is the sign for the lowest number, 1000, and all the subsequent full thousands (up to 9000) are formed by changing the hand shape. The sign 1000 may be converted into a plural by iterating the end part of the original pivot movement. At the same time, the hand typically moves slightly to the ipsilateral side (Jantunen and Savolainen 2002).

All the thousands (also those above 9000) may be formed with the strategy illustrated in Figure 24. The linguistic means underlying this strategy is sequential compounding. In the strategy, the sign for the basic numbers 1-9, tens or hundreds is compounded with a T-initialised lexeme meaning 'thousand' or 'ton' (Jantunen and Savolainen 2002).
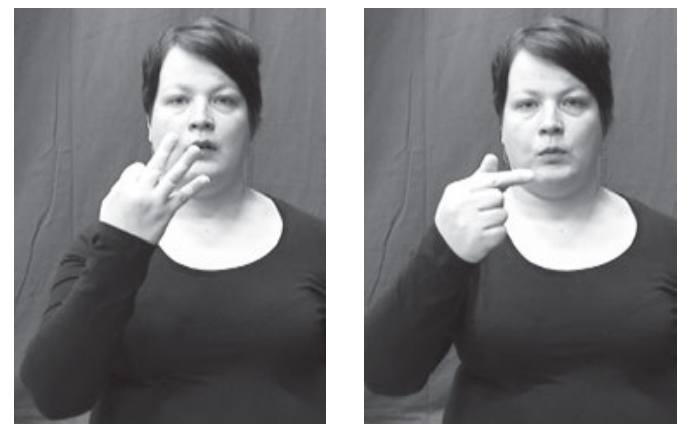

Figure 24. Number 8000 constructed by compounding sequentially 8 and T-initialised lexeme meaning 'thousand' or 'ton'. The T-initialised lexeme is produced with a straight forwards directed movement.

\section{Millions}

The basic sign for 'million' (MILLION-A) is shown in Figure 25. The sign is produced with a fist hand shape, the palm facing away from the signer. The
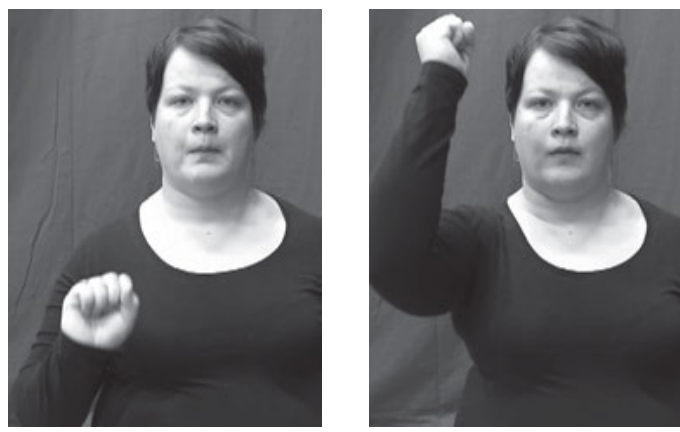

Figure 25. FinSL sign MILLION-A. The sign includes a repeated rotating wrist movement. 
movement of the hand is a complex movement involving a straight upwards path movement and a repeating rotating movement produced from the wrist joint. The sign may be modified for plurality ('millions') in the same way as has been described for 10, 100, and 1000 (Jantunen and Savolainen 2002). The signs for millions from two million upwards are produced by means of compounding: the first part of the compound is the number sign 2-999 and the second part is the sign MILLION-A.

The sign MILLION-A has a variant MILLION-B that is produced without the wrist movement. MILLION-B cannot be modified for plurality (Jantunen and Savolainen 2002).

\section{Billions}

FinSL has two signs meaning 'billion', both described in Figure 26. Subsequent billions are constructed through sequential compounding. Note that the sign BILLION-B resembles the two signs for 'million', the nonmanual feature as well as the amplitude and strictness of the movement being the key distinguishing factors.
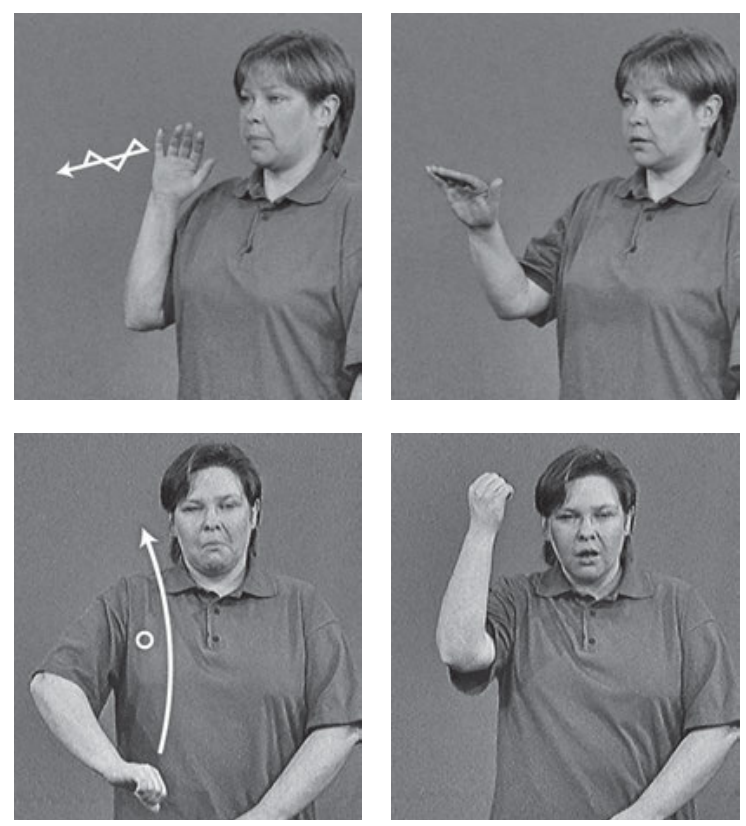

Figure 26. FinSL signs BILLION-A (upper row), including finger wiggling, and BILLION-B (bottom row), including nonmanual emphasis (images from Jantunen \& Savolainen 2002). 


\section{Fractions}

Fractions of numbers may be constructed in several ways in FinSL, depending partly on the context. Of the different ways mentioned by Sakara, de Vos and Zeshan (2012), FinSL employs them all: written language-based strategies, the sign HALF and its derivatives, and the spatial arrangement of numbers.

Concerning written language-based strategies, FinSL uses both the sign PERCENTAGE as well as the signs COMMA and DOT to indicate fractions (e.g. 5 PERCENTAGE for $5 \%$ and 3 COMMA 5 for $3 \frac{1}{2}$ ). However, the use of these strategies outside the formal and written domain is relatively rare.

The FinSL sign for HALF is produced by "cutting off" the index finger of the non-dominant hand with the index finger of the dominant hand. The sign HALF may be compounded with any cardinal number to produce the relevant 'halves' (e.g. 3 HALF for 31/2).

FinSL also has independent one-handed lexemes for the fractions $1 \frac{1}{2}$, $2 \frac{1}{2}$, and $3 \frac{1}{2}$. These are illustrated in Figure 27. These fractions may also be produced with two-handed forms in which the sign HALF is used as a basis. In these forms, however, unlike in the basic form of the sign HALF, the "cutting off" movement of the dominant hand is repeated; the non-dominant hand has the configuration corresponding to signs $2-4$ (with a diagonal orientation).
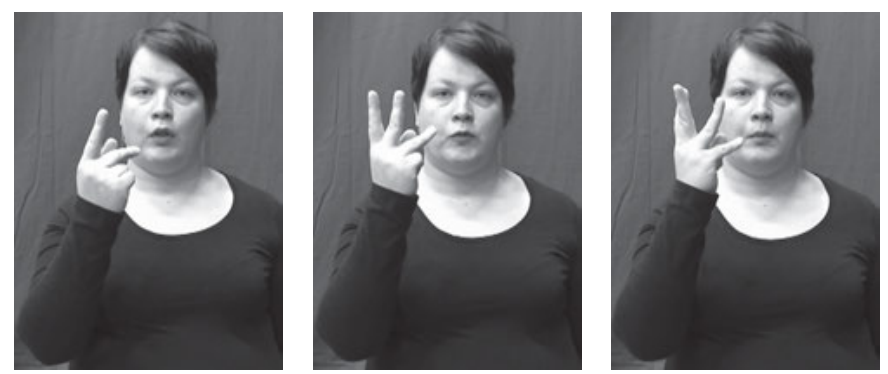

Figure 27. FinSL signs for $1 \frac{1}{2}, 2 \frac{1}{2}$, and $3 \frac{1}{2}$.

The spatial arrangement of numbers may be used in different ways to indicate fractions. For example, producing a number 1-8 a bit higher than the level of the chest, then rotating the wrist so that the palm faces forwards while at the same time moving the hand a bit downwards, and producing another number 1-8 (palm facing forwards), constructs fractions such as $1 / 3$, $4 / 5$, and $7 / 8$. Moreover, especially in the field of mathematics, all the fractions may be constructed by producing any number sign above any other (no orientation changes) as long as there is a line drawn between the two levels; 
the line may be drawn either with the dominant hand index finger or represented with the arm of the non-dominant hand.

\subsubsection{Ordinal numbers}

FinSL has independent lexemes for the ordinals 1-9. This paradigm is demonstrated in Figure 28.
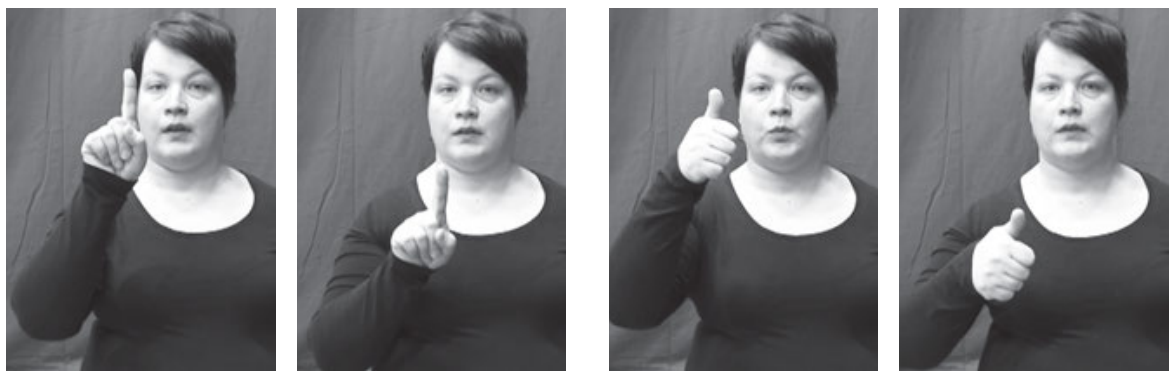

Figure 28. FinSL ordinals 1st (left) and 9th (right).

The FinSL ordinal number system follows the pattern (iii) of Stolz and Veselinova's (2008) typology, that is, the ordinals are derived from the cardinal numbers. The use of the pattern differentiates FinSL from the surrounding Finnish language, which employs the pattern (vi) (i.e. 'first', 'second', 'three-th'...). The main reason for the difference between FinSL and Finnish in this case is historical: like the FinSL cardinals, so too the FinSL ordinals (1-8) were devised by Carl Oscar Malm in the middle of the $19^{\text {th }}$ century (Hirn 1909)

The FinSL ordinal number system is a closed system: it does not extend beyond 9. For its construction, the system is based on adding to the cardinal number a short downwards movement and changing the orientation of the hand so that all the numbers are produced with the palm facing forwards. Similar characteristics have also been identified in other sign languages (Sakara, de Voss and Zeshan 2012).

Ordinal numbers from 1 to 5 may also be expressed by pointing with the fingers of the non-dominant hand. However, this option is restricted only to specific semantic domains, most notably to that concerning the number of brothers and sisters (Sakara, de Voss and Zeshan 2012).

Ordinal numbers from 10 onwards may be expressed in FinSL with the Finnish written language-based strategy of compounding the cardinal sign with the sign DOT. For example, the notion of "20th" is signed by producing the cardinal sign 20 followed by DOT. 


\subsubsection{Numeral incorporation}

In FinSL, numeral incorporation has been documented in various semantic domains including time units, monetary units, and educational levels. It is also used when talking about which floor something is located on, how many times an event has occurred and when stating, for example, the number of objects (Jantunen and Savolainen 2002). Numeral incorporation also occurs with classifier hand shapes that correspond to the numeral hand shapes 1 to 5 (Rissanen 1998). All the instances will be dealt with in more detail below.

\section{Time units}

The generic time-referring lexemes HOUR, WEEK, and MONTH (see Figure 29) all allow numeral incorporation in FinSL. The (dominant) hand configuration of these lexemes may be replaced with the hand configuration of the cardinal signs $1-8$ (i.e. signs without movement) in order to produce signs that refer to the specific number of hours, weeks, and months (e.g. FIVE\#HOURS, TWO\#WEEKS, EIGHT\#MONTHS).
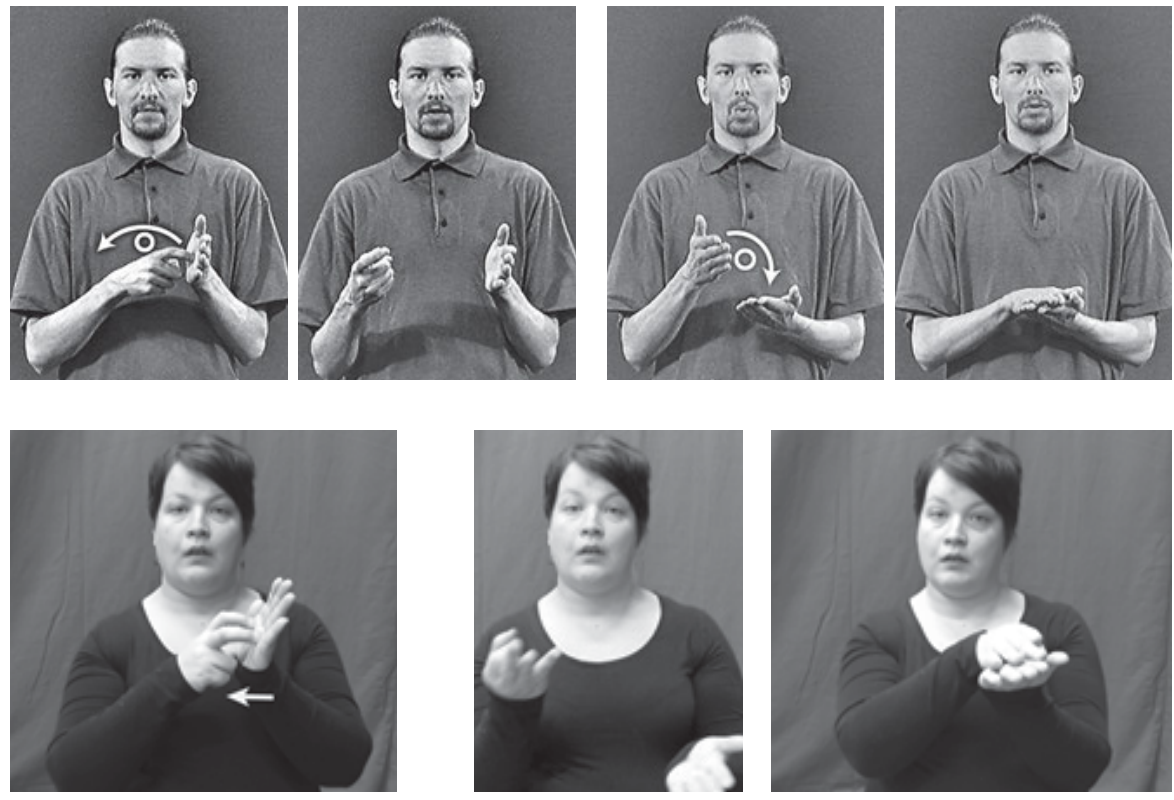

Figure 29. FinSL signs WEEK and MONTH (top and middle row, images from Malm 1998) and TWO\#WEEKS and EIGHT\#MONTHS (bottom row). 
The generic lexemes DAY and YEAR (Figure 30) do not allow numeral incorporation for the purpose of referring to the number of days or years. Instead, in order to refer to these temporal concepts, FinSL uses the paradigms illustrated in Figure 30 (bottom row). The forms in both paradigms may be considered to be based on the lexemes DAY and YEAR, and the change of the hand shape features between different forms may be analyzed as a form of numeral incorporation. When speaking about the age of people or animals, the movement of the YEAR-based forms tends to be produced only from the wrist joint (Jantunen and Savolainen 2002).
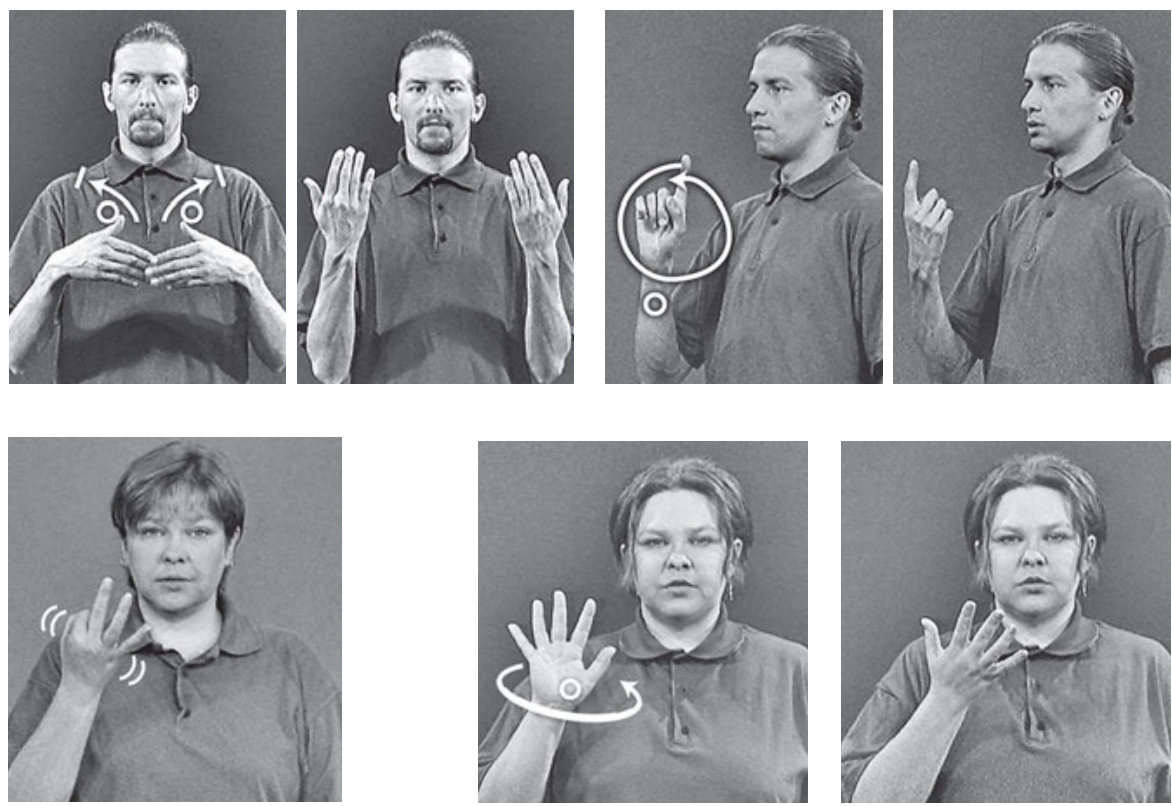

Figure 30. FinSL signs DAY and YEAR (upper and middle row, images from Malm 1998) as well as EIGHT\#DAYS and FIVE\#YEARS (bottom row, images from Jantunen \& Savolainen 2002).

Semantically all the past and/or future directed signs TOMORROW, YESTERDAY, NEXT-WEEK, LAST-WEEK, EVERY-WEEK, NEXTYEAR, LAST-YEAR, and EVERY-YEAR (see Figure 31) also allow numeral incorporation. The highest number that may be included in these signs is, again, 8 (e.g. EIGHT\#WEEK-AGO, EIGHT\#YEAR-FROM-NOW). However, with the lexemes TOMORROW and YESTERDAY, the count does not typically surpass 4 (e.g. FOUR\#DAY-AGO). 

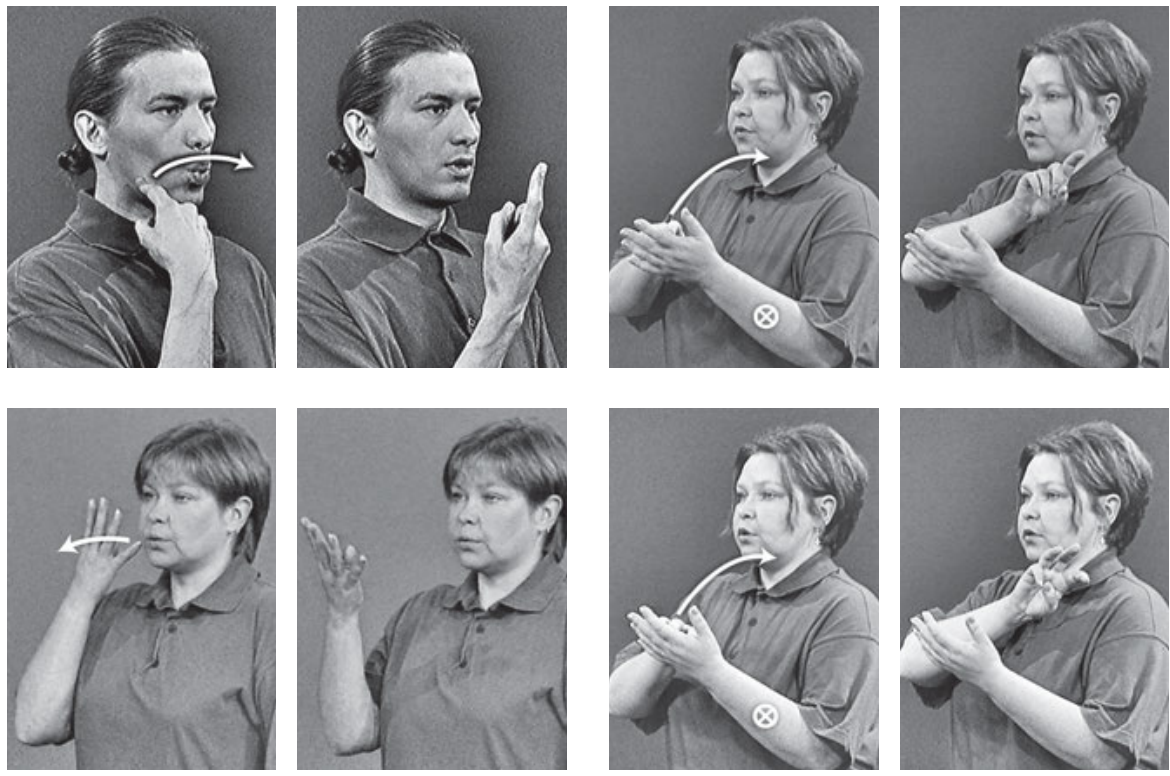

Figure 31. FinSL signs TOMORROW and LAST-WEEK (top row) as well as FOUR\#DAYS-FROM-NOW and THREE\#WEEKS-AGO (bottom row) (images from Malm 1998 and Jantunen \& Savolainen 2002).

In addition to the temporal expressions described above, FinSL has a rich system for referring to the time on the clock. This system is highly iconic in that it is based on the circular face of the clock. The system has been described in detail in Jantunen and Savolainen (2002).

\section{Monetary units}

The currency of Finland is the Euro. To express small amounts of euros, the sign EURO may be incorporated with the numbers 1-4. However, it appears that the more common strategy to express even these smaller amount of euros is to use sequential compounding (i.e. 3 EURO for ' 3 euros'). The sign for CENT (a hundredth of a euro) does not allow numeral incorporation.

\section{Educational levels}

FinSL uses numeral incorporation to express educational levels in primary and secondary school. The forms in the paradigm resemble closely the names for the numbers 1-9. However, in the signs for educational levels, the movement is more horizontal (Jantunen and Savolainen 2002). The paradigm 
extends to the number 9. Year ten (optional in the Finnish school system) is constructed sequentially by producing the signs TEN and CLASS.

\section{Floors of buildings}

The fact that something is located on the third or seventh floor may be expressed with the paradigm illustrated in Figure 32. With these forms, the location of the hand rises with the number of floors (Jantunen and Savolainen 2002). The paradigm extends to the number eight, after which a sequential strategy ("number" plus FLOORS) is used.
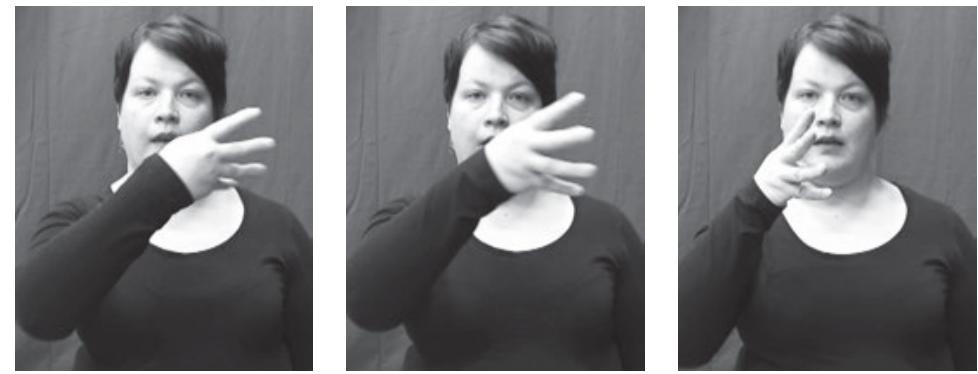

Figure 32. The sign AT-THE-FOURTH-FLOOR.

\section{Number of occasions}

To say, for example, how many times an event has occurred, FinSL uses either the sign OCCURRENCE-A or OCCURRENCE-B (Figure 33). Of these, OCCURRENCE-A is used only in sequential structures (e.g. SEVEN OCCURRENCE-A for 'seven times'). OCCURRENCE-B, however, may be incorporated with numbers $1-4$ to produce meanings 'one time'-'four times'. From 5 onwards, also OCCURRENCE-B is used only sequentially.
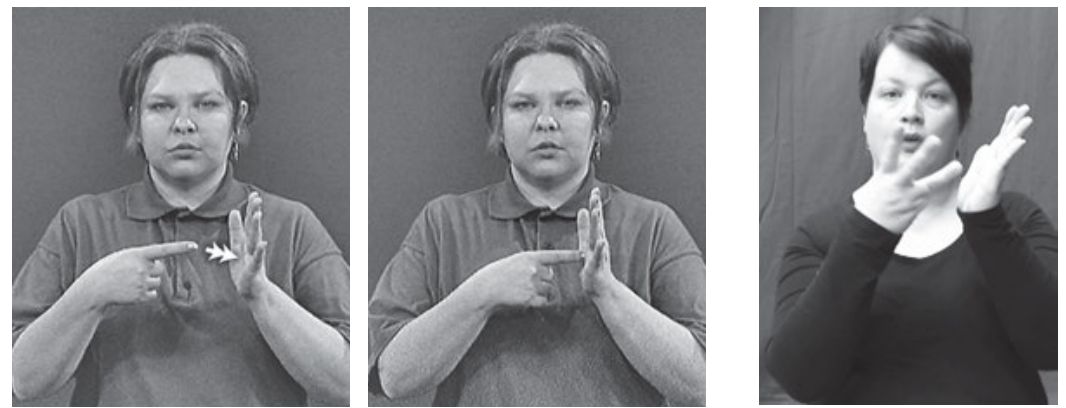

Figure 33. FinSL signs OCCURRENCE-B (left, images from Jantunen \& Savolainen 2002) and THREE\#OCCURRENCE-B (right). 
There is also another paradigm in FinSL to express the fact that something has occurred 1-8 times (Figure 34). In this paradigm, the form with the meaning 'once' is suppletive whereas the forms 'two times'-'eight times' are formally connected and analyzable as being formed through numeral incorporation.
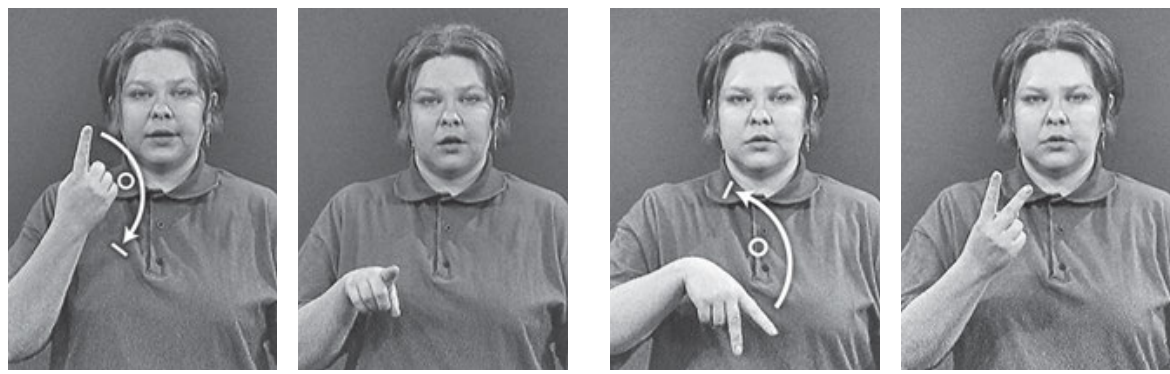

Figure 34. FinSL signs ONCE (left) and TWO\#TIMES (right) (images from Jantunen \& Savolainen 2002).

\section{Number of objects}

Two variants of the FinSL sign meaning 'piece' are given in Figure 35. Both forms allow numeral incorporation up to the number 8 .
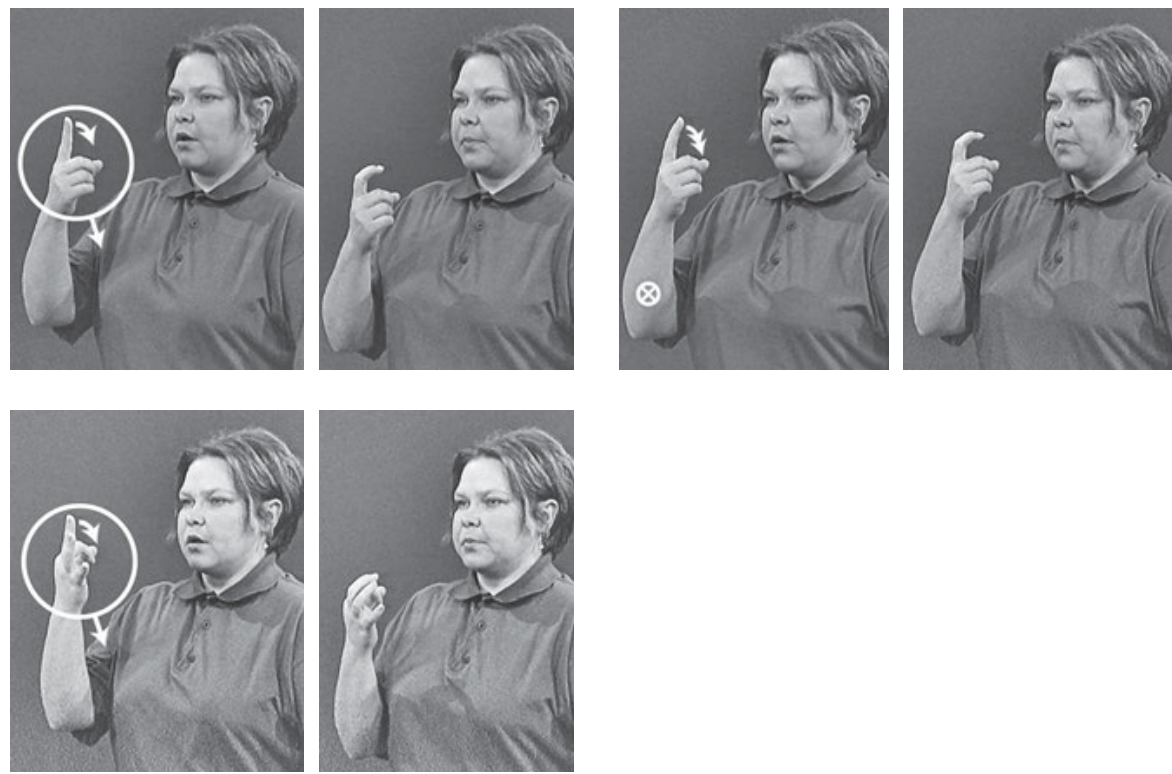

Figure 35. FinSL signs (upper row:) PIECE-A, PIECE-B, and (bottom row:) EIGHT\#PIECE-A (images from Jantunen \& Savolainen 2002). 


\section{Numeral incorporation with classifiers}

The classifier (CL) hand shape that refers to the standing human figure allows numeral incorporation in FinSL (Rissanen 1998). As in most sign languages (Sakara, de Vos and Zeshan 2012), an upright index finger (G-hand) signals 'one upright person' in FinSL but an upright index and middle finger (V-hand) signal 'two upright people'. For example:

(1) WOMAN CL-G-"walk past"-right-left

'A woman walks past.'

(2) TWO WOMAN CL-V-"walk past"-right-left

'Two women walk past.'

The hand shape may be changed to correspond to the numbers 3,4 , or 5 , in which case the meaning of the corresponding utterance changes to 'three people', 'four people', or 'five people'. The hand shape for 'five' can also be used for uncountable quantities, as in the following, where the addition of the non-dominant hand further emphasises the uncountable plural reading:

(3) PEOPLE both_hands:CL-5-"go past quickly"-right-left 'People went past quickly.'

The G-hand shape and its quantity-expressing derivatives may also refer to long solid inanimate oblong-shaped objects such as pencils or knitting needles. Also other classifier hand shapes (e.g. G-hook) based on extending fingers from the hand may be modified for quantity (e.g. V-hook for 'two hook-like objects').

\section{Conclusions}

The basic categorisation of colour terms and (cardinal) numbers in FinSL is similar to Finnish, the majority spoken language in Finland. The kinship system is also similar to the Finnish system, although some terms are missing in FinSL terminology.

With regard to kinship terms, FinSL includes terms for both core family members and non-core family members, as well as terms for blended 
families. For some terms there is a gender distinction, similarly to Finnish. Structurally, the terms can be single signs or compounds, which mostly resemble the structure of Finnish kinship terms. FinSL kinship terms also sometimes exhibit iconicity, but not necessarily in the same way as in other sign languages.

In addition to single colour signs, FinSL uses complex colour constructions and morphological modification of the manual sign along with additional facial expressions indicating saturation, changes in the colour spectrum and hedging. The colour terms in FinSL are semantically related to objects, as in many sign languages, but they do not have contact-induced motivation from Finnish. Although FinSL is a young language it has a wide colour vocabulary, as does Finnish, which is evidence of the contact between these two languages.

The FinSL number system has been specially devised and - perhaps partly because of this - it resembles, in its arithmetic basis, the system used in the Finnish language. However, decimal systems are widely used in the world's languages, and the underlying similarity between FinSL and Finnish should not be over-emphasised. The main differences between FinSL and Finnish numbers are found in the systems used to express ordinals: the two languages belong to different types. Moreover, the use of numeral incorporation distinguishes FinSL from Finnish, which does not allow such a process.

\section{Acknowledgements}

We want to thank our colleagues Ulla-Maija Haapanen, Minttu Laine, Eija Jääskeläinen and Tuija Wainio for assisting in the collection of the material as well as the informants who kindly took part in the discussions in the video recording sessions.

\section{Notes}

1. Sign Language Typology

https://www.uclan.ac.uk/schools/journalism_media_communication/islands/ typology/index.php 


\section{References}

Berlin, Brent \& Paul Kay. 1969. Basic Colour Terms: Their Universality and Evolution. Berkeley: University of California Press.

Comrie, Bernard. 1981. Language universals \& Linguistic Typology. The University of Chicago Press: Chicago.

Comrie, Bernard. 2008. Numeral bases. In M. Haspelmath, M. Dryer, D. Gil \& B. Comrie (Eds.), The world atlas of language structures, pp. 530-533. Oxford University Press: Oxford.

Conklin, H. C. 1973. Color Categorisation. American Anthropologist, New Series, 75, 4: 931-942.

Fischer, Susan. 1996. By the Numbers: Language-Internal Evidence for Creolization. International Review of Sign Linguistics 1:1-22.

Fuentes, M. \& L. Tolchinsky. 2004. The Subsystem of Numerals in Catalan Sign Language: Description and Examples from a Psycholinguistic Study. Sign Language Studies 5:94-117.

Geer, L. 2011. Kinship in Mongolian sign language. Sign Language Studies 11, 2011: 594-605.

Greenberg, Joseph H. 1966. Language universals with special reference to feature hierarchies. Janua Linguarum, Series Minor 59. The Hague Mouton.

Greenberg, Joseph H. 1990. Universals of kinship terminology: Their nature and the problem of their explanation. In K. Denning \& S. Kemmer (eds.) On language: Selected writings of Joseph Greenberg. Stanford: Stanford University Press, 310-327.

Hirn, J. 1909. Huru återgivas räkneorden på åtbördsspråket? [How to express numbers in sign language?] Dövstummas Jul 1909:8-9.

Hollman, Liivi \& U. Sutrop. 2010. Basic Color Terms in Estonian Sign Language. Sign Language Studies 11, 2: 130-157.

Jantunen, Tommi. 2001. Suomalaisen viittomakielen synnystä, vakiintumisesta ja kuvaamisen periaatteista [On the birth, change, and principles of description in FinSL]. KL Support Oy: Helsinki.

Jantunen, Tommi \& Leena Savolainen. 2002. Numeroita ja lukumäärien ilmaisuja. Suomalaisen viittomakielen perussanakirja. Täydennysosa 1 [Numbers and numeral expressions. Basic dictionary of FinSL. Supplement 1]. KL Support Oy: Helsinki.

Jantunen, Tommi \& Ritva Takkinen. 2010. Syllable structure in sign language phonology. In D. Brentari (Ed.), Sign Languages, pp. 312-331. Cambridge University Press: Cambridge.

Kay, Paul. \& Luisa Maffi. 1999. Color appearance and the emergence and evolution of basic color lexicons. American Anthropologist 101, 4: 743-760. 
Kay, Paul. \& Luisa Maffi. Colour terms. In M. Haspelmath, M. Dryer, D. Gil \& B. Comrie (Eds.), The world atlas of language structures, pp. 132-135. Oxford University Press: Oxford.

Kivinen, I. 2007. Värinimitykset syntysuomalais-ugrilaisissa kielissä, lähtökohtana 'musta'. (Colour terms in Finno-Ugric languages, 'black' as a starting point). Pro gradu -työ. Helsingin yliopisto, Suomalais-ugrilainen laitos, suomalaisugrilainen kielentutkimus.

Koski, M. 1983. Värien nimitykset suomessa ja lähisukukielissä. Suomalaisen kirjallisuuden seuran toimituksia 391. Savonlinna: SKS.

Liddell, Scott K. 1996. Numeral incorporation and bound roots: An analysis of simple and complex numeral incorporation forms. Manuscript.

Malm, Anja. 1998 (Ed.). Suomalaisen viittomakielen perussanakirja. KL Support Oy: Helsinki.

Massone, Maria I. \& Robert E. Johnson. 1991. Kinship terms in Argentine sign language. Sign Language Studies 73, 1991: 347-360.

McKee, David., Rachel McKee \& G. Major. 2011. Numeral Variation in New Zealand Sign Language. Sign Language Studies 12:72-97.

Nonaka, Angela M. 2004. The forgotten endangered languages: Lessons on the importance of remembering from Thailand's Ban Khor sign languages. Language in Society 33, 5: 737-767.

Nyst, Victoria. 2007. A Descriptive Analysis of Adamorobe Sign Language (Ghana). Utrecht: LOT.

Paunu, J. 1992. Viito elävästi 2. Helsinki: Kuurojen Liitto ry.

Peng, F. C. C. 1974. Kinship signs in Japanese sign language. Sign Language Studies 5, 1: 31-47.

Rissanen, T. 1998. The categories of nominals and verbals and their morphology in Finnish Sign Language. Licentiate Thesis in General Linguistics, University of Turku, Finland.

Sagara, Keiko, Connie de Vos \& Ulrike Zeshan. 2012. Nominal number in signed languages. Questionnaire. iSLanDS centre, Preston.

Salmi, E. 2010. Linguistic turns in teaching of the deaf in Finland. Series E. HUMAK Publications 2. Helsinki: Humanistinen ammattikor-keakoulu - HUMAK.

Shusky, E. L. 1965. Manual for kinship analysis. New York: Holt, Rinehart, Winston.

Stolz, Thomas \& Ljuba Veselinova. 2008. Ordinal numerals. In M. Haspelmath, M. Dryer, D. Gil \& B. Comrie (Eds.), The world atlas of language structures, pp. 218-221. Oxford University Press: Oxford.

Wallace, A. F. C. \& J. Atkins. 1960. The meaning of kinship terms. American Anthropologist 62: 57-80.

Velupillai, V. 2012. An Introduction to Linguistic Typology. Amsterdam: John Benjamins Publishing Company. 
Wilkinson, Erin L. 2009. Typology of signed languages: Differentiation through kinship terminology. Ph.D. diss., University of New Mexico, Albuquerque.

Woodward, James C. 1978. All in the family: Kinship lexicalization across sign languages. Sign Language Studies 19, 1978: 121-138. 1989. Basic Color Term Lexicalization across Sign Languages. Sign Language Studies 63: 145-152.

\section{Summary of the symbols used in the text} one sign (FATHER-IN-LAW)
$+\quad$ a compound (two sign form a concept e.g. FATHER+MOTHER for 'father's mother')
$\wedge \quad$ a compound (made up of two signs which undergo phonological processes)
! a sign modified by an intensified movement (!RED! for strong red)
$\mathrm{xx} \quad$ iterated movement (SLIGHT-REDxx for slightly red)
\# an incorporated number
CL-G A CL-"letter" notation in the beginning of the gloss indicates that the cor- responding sign contains a classifier handshape.

-"come to a stop" The end part of the gloss in classifier signs describing the signs' -right-left movement. The written sequence in between the quotation marks describes the overall manner of the movement. Labels "right" and "left" describe the relative direction of the movement. 